\title{
Galectin-3 in M2 Macrophages Plays a Protective Role in Resolution of Neuropathology in Brain Parasitic Infection by Regulating Neutrophil Turnover
}

\author{
Fredice 0. Quenum Zangbede, Arun Chauhan, Jyotika Sharma, and Bibhuti B. Mishra \\ Department of Biomedical Sciences, School of Medicine \& Health Sciences, University of North Dakota, Grand Forks, North Dakota 58202
}

\begin{abstract}
Macrophages/microglia with M2-activation phenotype are thought to play important anti-inflammatory and tissue reparative functions in the brain, yet the molecular bases of their functions in the CNS remain to be clearly defined. In a preclinical model of neurocysticercosis using brain infection with a parasite Mesocestoides corti, we previously reported the presence of large numbers of M2 cells in the CNS. In this study using female mice, we report that M2 macrophages in the parasite-infected brain display abundant galectin-3 expression. Disease severity was increased in Galectin- $3^{-/}$mice correlating with increased neurological defects, augmented cell death and, importantly, massive accumulation of neutrophils and M2 macrophages in the CNS of these mice. Because neutrophil clearance by efferocytosis is an important function of M2 macrophages, we investigated a possible role of galectin-3 in this process. Indeed, galectin-3-deficient M2 macrophages exhibited a defect in efferocytic clearance of neutrophils in vitro. Furthermore, adoptive transfer of M2 macrophages from galectin-3-sufficient WT mice reduced neutrophilia in the CNS and ameliorated disease severity in parasite-infected Galectin- ${ }^{-/-}$mice. Together, these results demonstrate, for the first time, a novel role of galectin-3 in M2 macrophage function in neutrophil turnover and resolution of inflammatory pathology in the CNS. This likely will have implications in neurocysticercosis and neuroinflammatory diseases.
\end{abstract}

Key words: brain; galectin-3; M2 macrophage; neurocysticercosis; neuroinflammation; neutrophil turnover

Significance Statement

Macrophages/microglia with M1-activation phenotype are thought to promote CNS pathology, whereas M2-anti-inflammatory phenotype promote CNS repair. However, the mechanisms regulating M2 cell-protective functions in the CNS microenvironment are undefined. The current study reports that helminth infection of the brain induces an increased expression of galectin-3 in M2 macrophages accumulated in the CNS. Using multiple experimental models in vivo and in vitro, they show that galectin-3 in M2 macrophages functions to clear neutrophils accumulated in the CNS. Importantly, galectin-3 in M2 macrophages plays a central role in the containment of neuropathology and disease severity. These results provide a direct mechanistic evidence of the protective function of $\mathrm{M} 2$ macrophages in the CNS.

\section{Introduction}

Macrophages/microglia respond to environmental cues by adopting polarized functional phenotypes between M1-proinflammatory or

Received Dec. 19, 2017; revised June 17, 2018; accepted June 19, 2018.

Author contributions: B.B.M. wrote the first draft of the paper; B.B.M. edited the paper. F.0.Q.Z. and B.B.M. designed research; F.0.0.Z., A.C., and B.B.M. performed research; F.0.Q.Z., J.S., and B.B.M. contributed unpublished reagents/analytic tools; F.0.Q.Z., J.S., and B.B.M. analyzed data; F.0.Q.Z., J.S., and B.B.M. wrote the paper.

This work was supported by National Institutes of Health Grant R21DE024300 to B.B.M., Grant P20GM113123 to B.B.M. and J.S., and Grants R21A1107457 and R01Al121804 to J.S. The Flow Cytometry core facility was supported by the National Institutes of Health COBRE Grant 5P20GM113123 and INBRE Grant 5P20GM103442. The Imaging core facilities were supported by NIH P30GM103329 and 5P20GM113123. We thank Dr. Christopher Jondle for technical help with efferocytosis experiment.

The authors declare no competing financial interests.

Correspondence should be addressed to Dr. Bibhuti B. Mishra, Department of Biomedical Sciences, School of Medicine \& Health Sciences, University of North Dakota, 1301 North Columbia Road, Grand Forks, ND 58202. E-mail: bibhuti.mishra@med.und.edu.
M2-anti-inflammatory (Murray and Wynn, 2011; Girgis et al., 2013; Gundra et al., 2014; Rückerl and Allen, 2014; Wynn and Vannella, 2016). M1 inflammatory effector cells generally promote the destruction of pathogens but cause widespread tissue damage when unchecked (Locati et al., 2013; Glass and Natoli, 2016). In addition, M1 macrophage/microglia are found to impair these CNS repair processes (Hu et al., 2015; Wohlfert et al., 2017). On the other hand, the M2 cells dampen excessive host inflammatory responses and promote tissue repair ( $\mathrm{Hu}$ et al., 2012; Franco and Fernandez-Suarez, 2015). In addition to these restorative processes in nervous tissue, $\mathrm{M} 2$ cells promote axonal remodeling and remyelination, oligodendrogenesis, and neuro-

DOI:10.1523/JNEUROSCI.3575-17.2018

Copyright $\odot 2018$ the authors $\quad 0270-6474 / 18 / 386737-14 \$ 15.00 / 0$ 
genesis (Miron et al., 2013). However, M2 cell involvement in CNS repair process has primarily been derived from in vitro studies or in vivo by selective depletion of these cells using chemicals. Mechanisms of their protective function in the CNS microenvironment are poorly understood.

M2 macrophage-associated response is a signature of helminth infections. Therefore, experimental models involving helminth infections in the CNS can be important to identify critical molecules and mechanisms in M2 macrophage/microglia functions to control brain pathology. In this regard, neurocysticercosis (NCC) is a common CNS parasitic disease caused by the presence of Taenia solium larvae in the CNS (White, 2000; Mahanty and Garcia, 2010). In a mouse model for NCC, in which mice are intracranially inoculated with a related helminth Mesocestoides corti (Cardona et al., 1999; Mishra et al., 2009; Alvarez et al., 2010a), an absence of M2 activation phenotype in the CNS is associated with severe neurological manifestations and mortality (Gundra et al., 2011; Mishra et al., 2011). Although the factors regulating M2 microglia/macrophages functions in NCC brains are not completely understood, of particular importance are glycan antigens containing terminal galactose and galactosamine that are released from the parasite in the CNS during murine as well as in human NCC (Alvarez et al., 2010a). These glycans released in the CNS microenvironment interact with the infiltrating macrophages (Dell et al., 1999; Alvarez et al., 2008), suggesting a possible role for the host lectin receptors in M2 cell-associated functions in the CNS, a highly understudied area.

Galectins are host lectins that can recognize pathogen- or hostderived $\beta$-galactosides (Rabinovich et al., 2002; Sato et al., 2009). They interact with carbohydrates through conserved carbohydraterecognition domains and contribute to homeostatic as well as immune-modulatory functions in several pathological conditions (Cooper et al., 2012). Among all the galectins (galectin-1 to galectin-15), galectin-3 is a unique member of the galectin family with the presence of unusual tandem repeats of proline- and glycine-rich regions (Cooper, 2002; Leffler et al., 2002). Although galectin-3 is known to influence M2 macrophage development and trafficking (MacKinnon et al., 2008), virtually nothing is known about its role in M2 macrophage/microglia functional phenotype in chronic CNS pathological conditions.

The goal of this study was to identify the expression and distribution of galectin-3 in a murine model of NCC. We compared the susceptibility and immunopathology, including the dynamics of leukocytes infiltration in the CNS, between the Galectin- $3^{-/-}$ and WT NCC mice. As galectin-3 was primarily detected in infiltrating M2 macrophages, galectin-3-sufficient M2 macrophages were adoptive transferred into the Galectin- $3^{-1-}$ NCC mice to analyze resolution of the CNS inflammation and disease severity. We here report a protective role of M2 macrophage-specific galectin-3 in mitigating CNS pathology and disease severity, by regulating efferocytosis-mediated neutrophil turnover during brain parasitic infection.

\section{Materials and Methods}

Mice. Female mice 4-6 weeks of age were used in this study. Galectin- $3^{-1-}$ mice on C57BL/6 were purchased from The Jackson Laboratory. C57BL/6 mice were obtained from Charles River and used as wild-type (WT) controls. Both WT and Galectin- $3^{-/-}$mice were bred in the animal facility of the University of North Dakota. The animals were used according to institutional and federal guidelines. Upon consideration of the relevant biological variables, we studied female mice because all the studies to date performed in the mouse model of NCC to recapitulate the disease development and neuropathology have been performed with female mice only.
Murine model of NCC. M. corti metacestodes used in this study were maintained in the peritoneal cavity of BALB/c mice by serial intraperitoneal inoculation as described by us previously (Mishra et al., 2008, 2011). The mouse model of NCC was developed as described by (Alvarez et al., 2010b). Briefly, anesthetized 4- to 6-week-old mice were intracranially injected with $50 \mu$ l of HBSS containing $\sim 40$ parasites. Mock control mice were intracranially injected with $50 \mu \mathrm{l}$ sterile HBSS using the same protocol. Death was recorded as infection-induced mortality. Mice displaying severe signs of distress (nonresponsiveness to cage tapping) were humanely killed and also recorded as infection-induced mortality. To analyze various immunopathological parameters at indicated times after inoculation, mice were anesthetized with $100 \mu \mathrm{l}$ of the above mixture, perfused through the left ventricle with $10 \mathrm{ml}$ cold PBS, before the brains were aseptically collected.

Parasite burden, histopathological and immunofluorescence (IF) analysis. From the perfused control and parasite-infected mice, the brains were quickly dissected out, embedded in optimal cutting temperature, and snap frozen. Serial horizontal cryosections of $10 \mu \mathrm{m}$ in thickness were placed on silane prep slides (Sigma-Aldrich). The slides were air-dried overnight and fixed in fresh acetone for $10 \mathrm{~s}$ at room temperature. Acetone-fixed sections were processed immediately for $\mathrm{H} \& \mathrm{E}$ or were wrapped in aluminum foil and stored at $-80^{\circ} \mathrm{C}$ to perform IF staining in the future.

For H\&E staining, after fixation in $4 \%$ formalin for $10 \mathrm{~min}$ at room temperature, slides were washed twice in deionized water, dehydrated for $30 \mathrm{~s}$ in $100 \%$ ethanol, stained $30 \mathrm{~s}$ in hematoxylin, and washed in distilled water for $2 \mathrm{~min}$ (Mishra et al., 2006, 2011). Tissue sections were stained with eosin for 15 s followed by 2 min treatment with $95 \%$ and $100 \%$ ethanol each. Slides were allowed to air dry, then submerged in xylene for $3 \mathrm{~min}$, and mounted using the cytoseal mounting medium (Stephens Scientific). The number and location of parasites were determined by microscopic examination of the stained tissues. Tissues were also analyzed for the presence or absence of infiltrating leukocytes.

For IF microscopy, the frozen brain tissue sections were stained with relevant antibodies to detect immune parameters, such as galectin-3, and immune cells (Mishra et al., 2013). Briefly, brain tissue sections were incubated with specific primary antibodies in staining buffer (PBS buffer with $3 \%$ host serum) to prevent nonspecific binding. After 45 min of incubations, sections were washed seven times 3 min each in $50 \mathrm{~mm}$ Tris- $\mathrm{HCl}, \mathrm{pH} 7.6$ with $0.1 \%$ Tween 20 and incubated with appropriate secondary antibodies in staining buffer for $30 \mathrm{~min}$. Sections were then washed seven times $3 \mathrm{~min}$ each in $50 \mathrm{~mm}$ Tris- $\mathrm{HCl}$, pH 7.6 with $0.1 \%$ Tween 20. For double IF staining, the above-mentioned procedures were sequentially repeated for each additional staining. The sections were mounted using FluorSave reagent (Calbiochem) containing $0.3 \mu \mathrm{M}$ DAPI (Invitrogen). Additional control staining was performed to rule out any nonspecific staining. In each case, sections were blocked with saturating concentrations of appropriate host serum antibodies to eliminate falsepositive staining due to FcR-mediated nonspecific binding. Staining in the absence of primary antibodies provided additional negative controls. Primary and secondary antibodies used for IF staining are as follows: rabbit anti-galectin-3 (Abcam) and AlexaFluor-546 or AlexaFluor-488 goat anti-rabbit (Invitrogen), rat anti-mouse 7/4 (Cedarlane), and AlexaFluor-546 or AlexaFluor-488 Goat anti-rat (Invitrogen), goat antimouse MGL1/2 (R\&D Systems), and AlexaFluor-546 or AlexaFluor-488 donkey anti-goat Alexa-488/Alexa-546 (Invitrogen). We evaluated tissue damage on frozen brain tissue sections from control and parasite-infected brains by performing the TUNEL staining as per the manufacturer's instructions (Millipore Bioscience Research Reagents). In all cases, the images were acquired using an Eclipse 80i upright microscope (Nikon) with an attached cooled RTke Spot 7.3 three spot color camera (Diagnostic Instruments). The images were processed and analyzed using Photoshop 7.0 software (Adobe).

Brain mononuclear cells isolation and flow cytometric analysis. Mononuclear cells from mouse brains were isolated as described previously (Mishra et al., 2011, 2016). To prepare single-cell suspension, each perfused brain was gently minced using Dounce homogenizer in $3 \mathrm{ml}$ of HBSS (without $\mathrm{Ca}^{2+}, \mathrm{Mg}^{2+}$ ) containing HEPES (10 mM) (Invitrogen). The mixture was suspended in $30 \%$ Percoll and then slowly overlaid on $70 \%$ Percoll (GE Healthcare), centrifuged at $500 \times g$ for $30 \mathrm{~min}$ at room 
temperature. The interface was collected, pelleted at $200 \times g$ for $5 \mathrm{~min}$ and resuspended in HBSS, washed three times in $1 \mathrm{ml}$ of HBSS with $0.1 \%$ BSA (Sigma-Aldrich), and quantified by trypan blue staining before performing flow cytometric analysis. Following antibodies were used for flow cytometry: FITC anti-mouse CD11b (clone M1/70), PE-Cy7 antimouse F4/80 (clone BM8), PE anti-mouse TCR $\gamma \delta$ (clone GL-3), PE-Cy7 anti-mouse Siglec F (clone FC50-2440), APC anti-mouse CD206 (clone C068C2), PE anti-mouse PD-L2 (clone T425), Pacific blue anti-mouse CD45 (clone 30-F11), and APC anti-mouse Ly6G (clone 1A8) antibodies (all from Biolegend), and PE-anti-mouse galectin-3 (clone eBioM3/38) from eBioscience.

Flow cytometric analyses for cell surface expression of relevant molecules were performed on a BD LSR II flow cytometer (BD Biosciences) as we have previously described (Mishra et al., 2009). For intracellular galectin-3 staining in macrophages/microglia, cells were rinsed and stained for relevant surface markers at $4^{\circ} \mathrm{C}$. Cells were fixed and permeabilized using fixation and permeabilization buffer (eBioscience) before intracellular galectin-3 was detected by staining in intracellular FACS buffer (eBioscience) containing PE anti-mouse galectin-3 (eBioscience) and analyzed on a BD LSRII flow cytometer (BD Biosciences).

$R N A$ isolation and $q R T-P C R$ analysis. The qRT-PCR analysis was performed as described by us previously (Chauhan et al., 2014; Sun et al., 2014). Total RNA from mock control and parasite-infected brains were isolated using Trizol reagent following the manufacturers' instructions (Invitrogen) and as described by us previously (Mishra et al., 2006, 2008). One microgram of total RNA from each sample was reverse transcribed into cDNA by using a high-capacity cDNA reverse transcription kit according to the manufacturers' instructions (Applied Biosystems). Transcript levels of galectin-3 or the housekeeping ribosomal 18 S RNA were analyzed by RT-PCR using specific primers: $18 \mathrm{~S}$ (forward) 5 '-CATGTG GTGTTGAGGAAAGCA-3' and(reverse) $5^{\prime}$-GTCGTGGGTTCTGCATG ATG-3', galectin-3 (forward) 5' -CAGTGCAGAGGCGTCGGGAAA-3' and (reverse) $5^{\prime}$-CTGCCCCAGCAGGCTGGTTT-3'. Expression levels of galectin-3 were normalized to the mRNA level of the housekeeping 18 $S$ RNA gene in the same sample. The fold change was calculated by dividing the normalized value of galectin-3 in parasite-infected brain samples with the corresponding normalized value in mock-infected brain samples.

Macrophage adoptive transfer. For adoptive transfer of M2 macrophages in vivo, bone marrow cells were isolated from WT mice and differentiated to macrophages as previously described (Chauhan et al., 2014; Gundra et al., 2017). Bone marrow-derived naive macrophages on day 6 of differentiation were exposed to IL-4 (20 ng/ml, PeproTech) for $24 \mathrm{~h}$ to generate the M2-anti-inflammatory phenotype, respectively, in vitro (Girgis et al., 2014; Gundra et al., 2014). The M2 macrophages were labeled with carboxyfluorescein succinimidyl ester (CFSE; Cell Trace CFSE Cell Proliferation Kit, Invitrogen) CellTracker at $37^{\circ} \mathrm{C}$ for $15 \mathrm{~min}$ as described by us previously (Jondle et al., 2016). The $5 \times 10^{6}$ labeled cells were then injected intravenously via tail vein (Jondle et al., 2016) into WT and Galectin- $3^{-/-}$mice intracranially infected with $M$. corti for $6 \mathrm{~d}$ before transfer. As control, WT and Galectin- $3^{-1-}$ mice undergoing NCC in the same experimental setup were injected with vehicle only. Twenty-four hours after transfer, brains were harvested and processed for various immunopathological analyses on parameters by following the abovementioned experimental protocols (see Results).

Ex vivo efferocytosis. For these studies, peritoneal neutrophils were isolated from WT mice 12-16 h after intraperitoneal injection of sterile $4 \%$ thioglycollate (BD Biosciences) (Swamydas et al., 2015). For macrophages, WT and Galectin-3 ${ }^{-1-}$ mice were injected intraperitoneally with $4 \%$ thioglycollate on day 0 . On days 0 and 2, mice were injected intraperitoneally with IL-4c mixture containing $5 \mu \mathrm{g}$ of recombinant murine IL-4 (PeproTech) and $25 \mu \mathrm{g}$ of anti-IL-4 mAB (11b11, BioXcellM), whereas control animals received vehicle, PBS. On day 4, peritoneal exudate cells were harvested and macrophages were analyzed for expression of M1/M2 mediators by flow cytometry and RT-PCR before they were used for efferocytosis analysis ex vivo. To compare efferocytosis by M2 macrophages induced by parasite infection, WT and Galectin- $3^{-1-}$ mice were infected intraperitoneally with $M$. corti (80-100 in numbers) and peritoneal exudate cells were harvested after $4-5$ weeks after infection to collect M2 cells. Mock control mice instead received vehicle (PBS). On day 4, peritoneal exudate cells were harvested to purify naive macrophages for their role in this process. To obtain neutrophils, WT mice were injected intraperitoneally with $4 \%$ thioglycollate for $16-18 \mathrm{~h}$.

The purity of the cells was ascertained by flow cytometry analysis (Ly6G ${ }^{+}$neutrophils $80 \%-85 \%$; F4/80 ${ }^{+}$macrophages $85 \%-90 \%$ ). Isolated neutrophils were labeled with CFSE (Cell Trace CFSE Cell Proliferation Kit, Invitrogen). Macrophages seeded on 6-well plates $\left(1 \times 10^{6}\right.$ cell $/ \mathrm{ml}$ ) were incubated with CFSE-labeled neutrophils at a ratio of 5:1 (neutrophils/macrophages). After $2 \mathrm{~h}$ of efferocytosis, noninternalized neutrophils were removed by washing thoroughly. Macrophages were scraped and stained with F4/80 and Ly6G antibodies for flow cytometry. Gating scheme to quantitate Ly6G ${ }^{-} \mathrm{F} 4 / 80^{+} \mathrm{CFSE}^{+}$efferocytic macrophages that had internalized labeled neutrophils is shown in Figure 8. For individual experiments, efferocytic index was calculated as a percentage of $\mathrm{Ly}_{6 \mathrm{G}}{ }^{-} \mathrm{F} 4 / 80^{+} \mathrm{CFSE}^{+}$macrophages from WT and Galectin-3 ${ }^{-1-}$ mice that engulfed neutrophils (Jondle et al., 2016).

Statistical analysis. The survival of the infected WT and Galectin- $3^{-1-}$ mice was compared using Log-rank (Mantel-Cox) Test. The statistical comparison between levels of host mediators was done with Student's $t$ test using Sigma Plot 8.0

\section{Results \\ Galectin-3 is abundantly expressed in M2 macrophage recruited into the CNS during murine NCC}

To examine the role of galectin-3 in parasite-infected brains, its transcript level of expression was determined by qRT-PCR using RNA from mock and $M$. corti intracranially infected brains. Increased mRNA expression of galectin-3 was observed at both 1 and 3 weeks after infection over mock control ( $\sim 27$-fold increase at 1 week after infection and $\sim 14$-fold increase at 3 weeks after infection) (Fig. 1A). To identify the cell-specific expression of galectin-3 protein, in situ coimmunostaining was performed on brain cryosections of mock control and parasite-infected mice. In mock-infected mice brains, galectin-3 was scarcely detected (Fig. 1B1). In contrast, parasite-infected brains exhibit abundant galectin-3 protein expression (Fig. 1B2,B3). Double IF staining on the parasite-infected brain sections showed an accumulation of large numbers of round monocyte/macrophage-like $\mathrm{CD} 11 \mathrm{~b}^{+}$or F4/ $80^{+}$cells in meninges and ventricles that displayed positive staining for galectin-3 (Fig. 1B3). We have previously reported that the infiltrating macrophages in the CNS of mice undergoing NCC display M2, but not M1, activation phenotype (Mishra et al., 2011) as these cells express Arg-1, YM1, Fizz1, and other M2 phenotypic cells surface markers MR1, MGL1/2, but not NOS2 (M1 activation phenotypic marker). Indeed, the MGL1/2 ${ }^{+}$infiltrating M2 macrophages (Mishra et al., 2011) were stained positive for galectin-3 (Fig. 1B4), suggesting that the M2 macrophages accumulating in the CNS during parasite infection abundantly express galectin-3. In addition, some microglia cells as determined by $\mathrm{CD}_{11 \mathrm{~b}^{+}}$staining combined with typical cell morphology and brain anatomical location exhibited galectin-3 expression (data not shown). Galectin-3 protein expression was largely undetected in other nervous tissue or immune cell types: CD11c (dendritic cells), $\alpha \beta$ T cells, $\gamma \delta$ T cells, neutrophils (7/4), and B cells (CD19) (data not shown).

To further characterize the cell-specific expression of galectin-3 in infiltrating macrophage and/or microglia as well as to identify its cellular localization, flow cytometric analysis was performed. It is important to note that CD $45^{\text {hi }} \mathrm{F} 4 / 80^{+}$cells in the CNS are known to be infiltrating macrophages, whereas $\mathrm{CD} 45^{\text {int }} \mathrm{F} 4 / 80^{+}$cells represent microglia. Consistent with IF microscopy analysis, galectin-3 was primarily detected in $\mathrm{CD} 45^{\mathrm{hi}} \mathrm{F} 4 / 80^{+}$macrophages in the CNS at both 1 and 3 weeks after infection (Fig. $2 B, C$ ). In contrast, a lower frequency of CD $45{ }^{\text {int }} \mathrm{F} 4 / 80^{+}$cells that are presumably mi- 
A

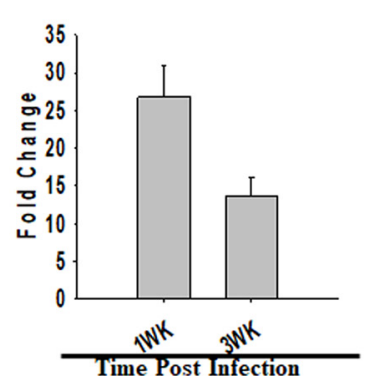

B

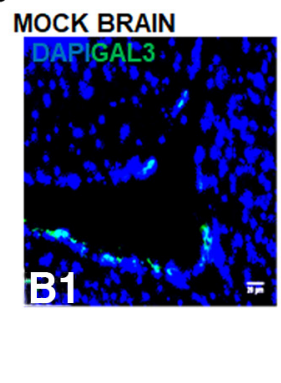

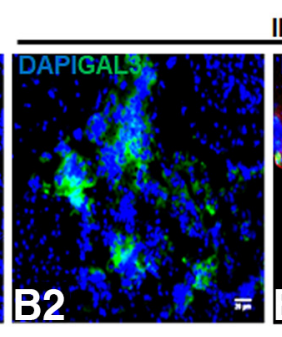

INFECTED BRAINS

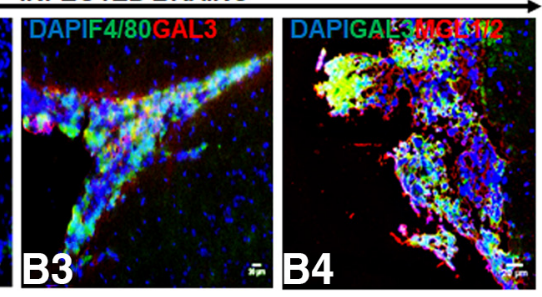

Figure 1. Expression and distribution of galectin-3 in the parasite-infected brains. qRT-PCR analysis and IF microscopy were performed on parasite-infected and mock control mice intracranially injected with helminth parasite M. corti. A, The total RNA was extracted from the brains at 1 and 3 weeks after inoculation, and mRNA expression of galectin-3 was measured by $q$ RT-PCR as described in Materials and Methods. The fold changes in parasite-infected brains were calculated over the levels in mock control mice using the formula $2^{-(\Delta \Delta C t)}$. Data shown are the mean $\pm S E M$ of 3 or 4 mice per time point in two independent experiments. $\boldsymbol{B}$, Double immunofluorescence staining was performed on brain tissue cryosections from mock (B1) or parasite-infected $\mathbf{C} 57 \mathrm{BL} / 6$ mice (B2-B4). Nuclei (blue) were stained with DAPI. Galectin-3 was stained using an affinity purified anti-mouse Galectin-3 goat lgG followed by AlexaFluor-488-labeled (green) goat anti-rabbit lgG. Galectin-3 expression was covisualized with macrophages using an affinity purified anti-mouse F4/80 AlexaFluor-488-labeled (green) (B3) or MGL1/2 + cells using an affinity purified anti-mouse MGL1/2 goat lgG followed by AlexaFluor-546-labeled (red) donkey anti-goat lgG (B4). Images shown are representative of 3 independent experiments with 3 or 4 mice each. Original magnification $\times 20$.

croglia displayed galectin-3-positive staining (Fig. $2 B, C$ ). Interestingly, the majority of the $\mathrm{CD} 45^{\mathrm{hi}} \mathrm{F} 4 / 80^{+}$cells exhibited intracellular staining of galectin-3 (Fig. $2 B, C$ ). In both 1 and 3 weeks after infection of mice brains, $80 \%-90 \%$ of the CD $45{ }^{\text {hi }} \mathrm{F} 4 /$ $80^{+}$cells were MGL1/2 ${ }^{+}$or PDL2 ${ }^{+}$(data not shown), indicating that the galectin-3 expression is largely localized to the M2 macrophages in the CNS of $M$. corti intracranially infected mice undergoing NCC.

\section{Galectin-3 ${ }^{-/-}$mice exhibit increased disease severity during murine NCC}

In light of abundant expression of galectin- 3 in M2 macrophages, we sought to examine the role of galectin-3 in overall disease severity during parasite infection of the brain. For this, the development of neurological signs and survival of WT and Galectin- $3^{-1-}$ were compared. Neurological signs related to intracranial $M$. corti infection, including abnormal vestibular function, tilted head, and cerebral abnormalities, were observed between 2 and 3 weeks after infection in WT mice. However, infected Galectin- $3^{-/-}$mice displayed these signs much earlier and were more accentuated between 2 and 3 weeks after infection. Importantly, M. corti-infected Galectin- $3^{-/-}$mice exhibited decreased survival compared with the WT (Fig. 3A). At 3 weeks after infection, only $40 \%$ ( 4 of 10 ) of the $M$. corti intracranially infected Galectin- $3^{-1-}$ survived the CNS infection as opposed to $100 \%$ (9 of 9 ) of the WT mice (Fig. $3 A ; p<0.005$ ). Together, these data suggest a protective role of galectin- 3 in the pathogenesis of CNS parasite infection, possibly relating to its expression in the infiltrating M2 macrophages in the CNS.

\section{Galectin-3 $3^{-/-}$mice exhibit no defect in parasite clearance or their segregation}

Microscopic analysis of the H\&E-stained serial brain cryosections was performed to determine the clearance of parasites and/or their extravasation into specific CNS areas in the absence of galectin-3. No statistically significant difference in the parasite loads was observed in the CNS of WT and Galectin- $3^{-/-}$NCC mice at 1 and 3 weeks after infection (Fig. 3B). Moreover, brain parenchyma or extraparenchyma of WT and Galectin- $3^{-1-}$ mice at 1 and 3 weeks after infection exhibited no statistically significant difference in parasite count (Fig. 3B), although the Galectin- $3^{-/-}$mice tended to exhibit relatively lower numbers of organisms in extraparenchymal regions (Fig. 3B). Thus, the protective function of galectin-3 did not appear to relate to parasite clearance and/or their segregation to specific CNS sites of infected mice.

\section{Galectin-3 ${ }^{-/-}$mice exhibit severe neuropathology}

We evaluated the gross CNS immunopathological changes in mock and intracranial M. corti-infected WT and Galectin-3 ${ }^{-1-}$ mice. H\&E-stained brain cryosections of the control animals of both strains that were intracranially inoculated with HBSS displayed similar normal brain tissue morphology with scarce presence of immune cells (Fig. 3C). In the parasite-infected WT mice brains, the presence of mixed leukocyte subsets was detected. A majority of these infiltrating cells appeared to be monocytes/ macrophages at both 1 and 3 weeks after infection (Fig. 3C, inset). In contrast, infected Galectin- $3^{-1-}$ mice brains appeared to exhibit an increased CNS inflammation with transiently higher numbers of infiltrating immune cells compared with WT mice. In addition to the high numbers of immune cells with morphology consistent with monocytes/macrophages, polymorphonuclear cells were abundantly detected between 2 and 3 weeks after infection in Galectin- $3^{-/-}$mice compared with their WT counterparts (Fig. $3 C$, inset, shown at 3 weeks after infection). To examine the impact of galectin-3 deficiency on the tissue pathology, TUNEL staining was performed on the brain tissue sections of WT and Galectin-3 $3^{-/-}$mice. Very little to no TUNEL ${ }^{+}$cells were detected in the CNS of mock (Fig. 3D) and at 1 week after infection (data not shown) in WT and Galectin- $3^{-/-}$mice. At 3 weeks after infection, the TUNEL staining remained low in the WT brains, which was in contrast to the Galectin- $3^{-/-}$brains that displayed increased TUNEL-detected staining at that time after infection (Fig. 3D). Interestingly, this increased TUNEL staining was detected in immune cells present in the extraparenchymal regions and surrounding nervous tissue cells in the CNS of Galectin- $3^{-/-}$mice. These data suggest that absence of galectin-3dependent responses leads to greater CNS inflammatory pathology during NCC.

To further examine the impact of galectin-3 deficiency on inflammatory response, levels of multiple inflammatory cytokines and chemokines in brain homogenates were compared between WT and Galectin- $3^{-/-}$mice intracranially inoculated with HBSS or M. corti (Fig. 4). CBA analysis for key inflammatory molecules TNF- $\alpha$, IL-1 $\beta$, and IL-12p70 showed low basal levels of these cytokines in WT and Galectin- $3^{-1-}$ mice brains (Fig. 4). In contrast, $M$. cort $i$-infected WT and Galectin $-3^{-/-}$mice brains 

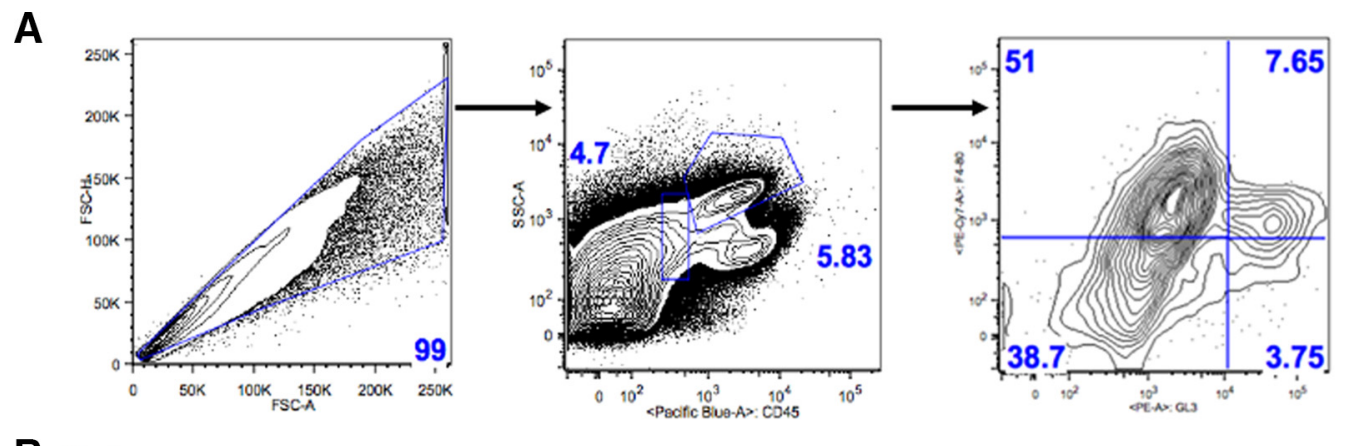

B Brain

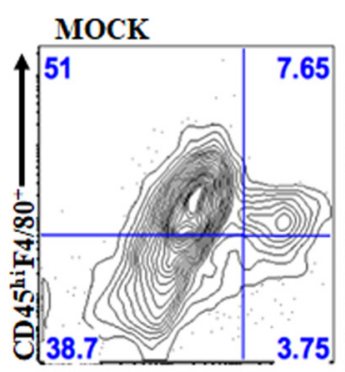

INFECTED

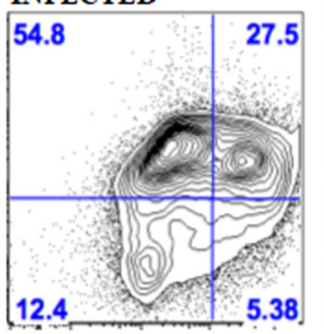

MOCK
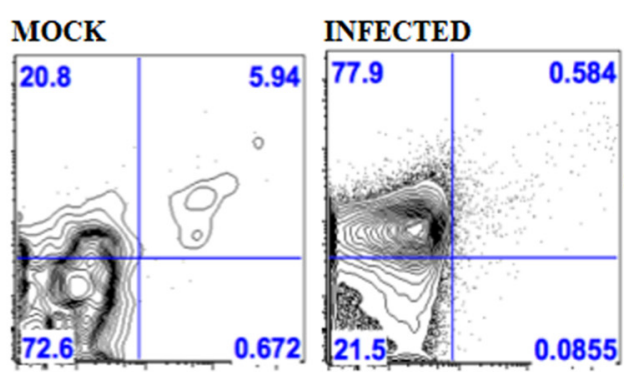

C
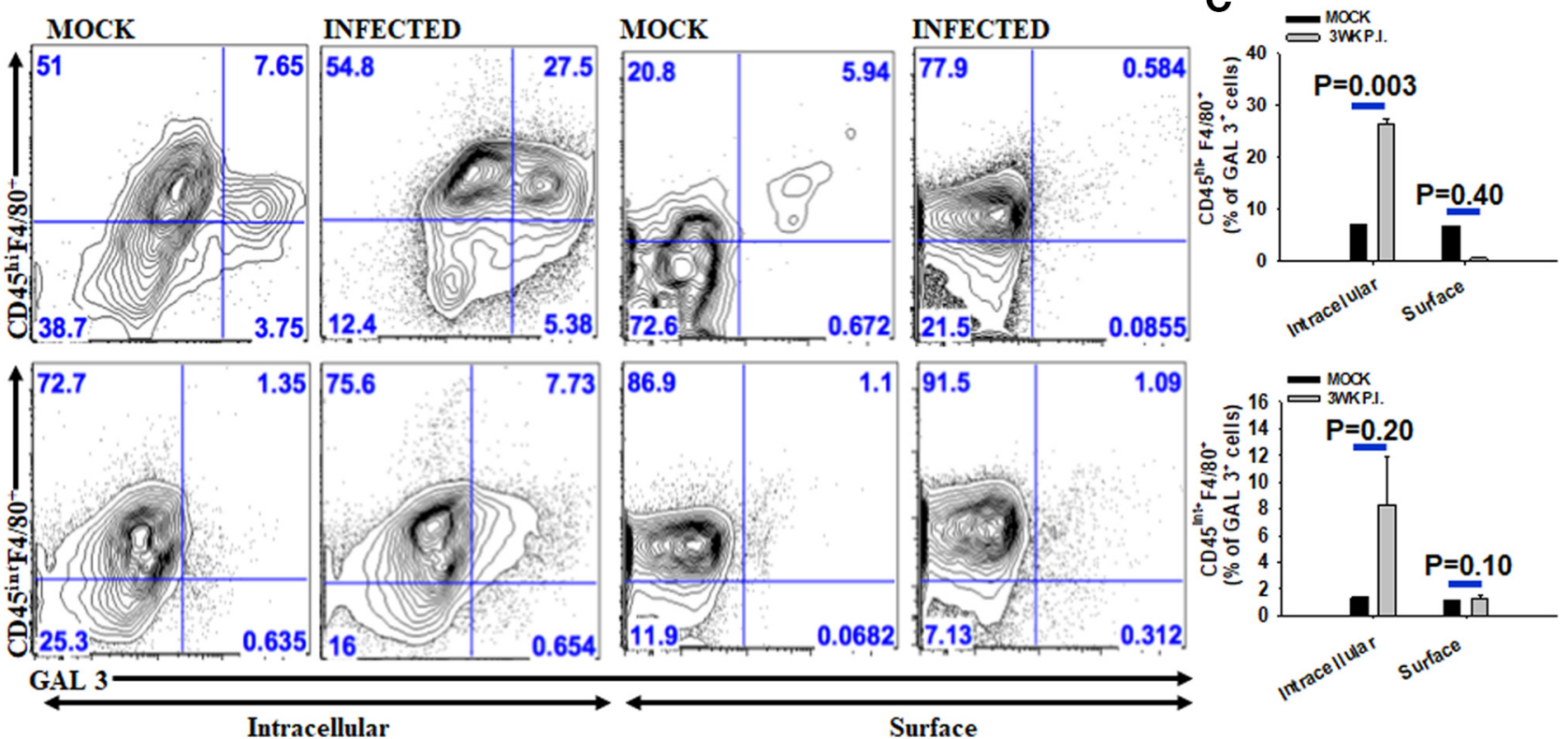

Intracellular

Surface

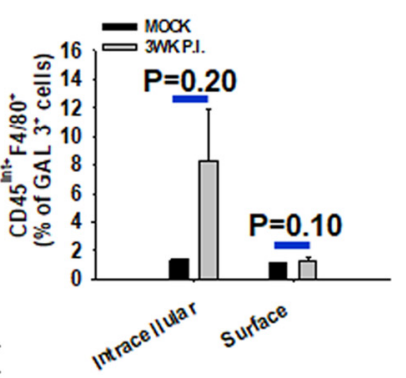

Figure 2. Infiltrating M2 macrophages in the parasite-infected brains express galectin-3 in the cytosol, but not on cell surface. Mice were injected intracranially with HBSS (mock) or 60 helminth parasite (infected), and brain mononuclear cells were isolated at 3 weeks after inoculation. $\boldsymbol{A}$, Schematic for gating $\mathrm{CD} 5^{+} \mathrm{F} 4 / 80^{+}$(macrophages/microglia) cells that express galectin-3. $\boldsymbol{B}$, Representative scatter plots from 3 independent experiments showing percentage of $\mathrm{CD} 45^{\mathrm{hi}} \mathrm{F} 4 / 80^{+}$(infiltrating macrophages) or $\mathrm{CD} 45^{\mathrm{int}} \mathrm{F} 4 / 80^{+}$(microglia) cells from the brains of mockinfected and parasite-infected mice exhibiting intracellular or cell surface expression of galectin-3. C, Galectin-3 expression was quantified in $\left(D 45^{\text {hi }} 54 / 80^{+}\right.$macrophages or $C D 45^{\text {int }} 54 / 80^{+}$ microglia from 3 independent experiments. CD45hiF $4 / 80^{+} \mathrm{GAL} 3^{+}$cells intracellular $(n=6) ; \mathrm{CD} 45^{\text {hif }} 4 / 80^{+}$GAL $3^{+}$cell surface $(n=6) ;\left(\mathrm{CD} 45 \mathrm{i}^{\text {nt }} \mathrm{F} 4 / 80^{+}\right.$microglia intracellular $(n=6)$; CD $45 \mathrm{i}^{\mathrm{nt}} \mathrm{F} 4 / 80^{+}$microglia surface $(n=6)$. $p$ values $(t$ test).

exhibited increased levels of these mediators at 1 and 3 weeks after infection, albeit there were no statistically significant differences in IL-1 $\beta$ and IL-12p70 levels between infected Galectin- $3^{-/-}$and WT mice (Fig. 4). TNF- $\alpha$ was detected at a lower level in Galectin- $3^{-1-}$ mice at 3 weeks after infection, compared with the WT counterparts (Fig. 4). On the other hand, significantly higher levels of neutrophil chemo-attractants (CXCL1) and monocyte/ macrophage chemo-attractants (CCL2, CCL4) were detected in the brain homogenates of parasite-inoculated Galectin-3 ${ }^{-/-}$ mice at 1 week after infection compared with the WT. Intriguingly, no significant differences in the levels of these chemokines were detected in the CNS of Galectin- $3^{-1-}$ mice at 3 weeks after infection (Fig. 4), a time of peak disease severity displayed by them. Our results suggest a possibility of higher accumulation of polymorphonuclear cells together with increased cell death in the CNS to be likely the cause of enhanced disease severity observed in Galectin- $3^{-/-}$mice after brain parasite infection.

Galectin- $3^{-/-}$mice display increased neutrophil and M2 macrophage accumulation in the CNS after parasite infection The majority of the immune cells recruited to the brain after parasite infection are macrophages ( $2-3 \mathrm{~d}$ after infection), $\gamma \delta \mathrm{T}$ cells (3-5 d after infection), dendritic cells ( 1 week after infection), $\alpha \beta$ T cells ( 1 week after infection), and B cells ( 3 weeks after infection) (Mishra et al., 2006, 2016; Gundra et al., 2011). In the M. corti-infected brains, macrophages are the most predominant leukocyte populations, whereas neutrophils are detected in relatively in low numbers throughout the infection process (Cardona et al., 1999). Within this context, H\&E analysis of the brain cryosections of M. corti parasite-infected Galectin- $3^{-/-}$mice appeared to display a massive increase in numbers of infiltrating cells with morphology consistent with neutrophils (Fig. 3C). To determine whether a deficiency of galectin-3 alters neutrophil numbers in the CNS, the expression of neutrophil marker $7 / 4$ was analyzed by in situ IF microscopy. In mock-infected brains of both WT and Galectin- $3^{-/-}$mice, $7 / 4+$ cells were scarcely detected (Fig. 5A). In the WT brain at 1 week after infection, little change in the numbers of $7 / 4+$ cells was detected compared with the mock control mice, which increased by 3 weeks after infection. Parasite-infected Galectin- $3^{-/-}$brains, on the other hand, exhibited a massive increase in $7 / 4+$ cells at 3 weeks after infection compared with WT mice (Fig. 5A). This suggested that the absence of galectin- 3 results in increased of neutrophils accumulation in the infected brain. 
A
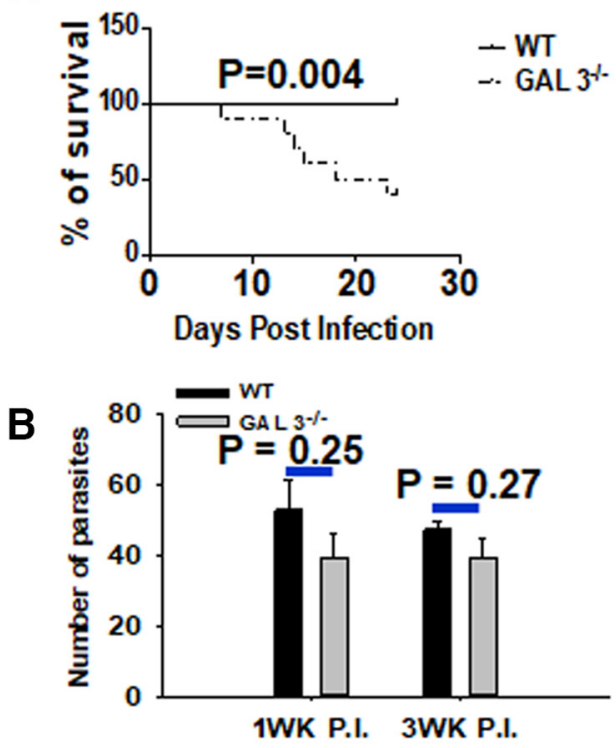

WB
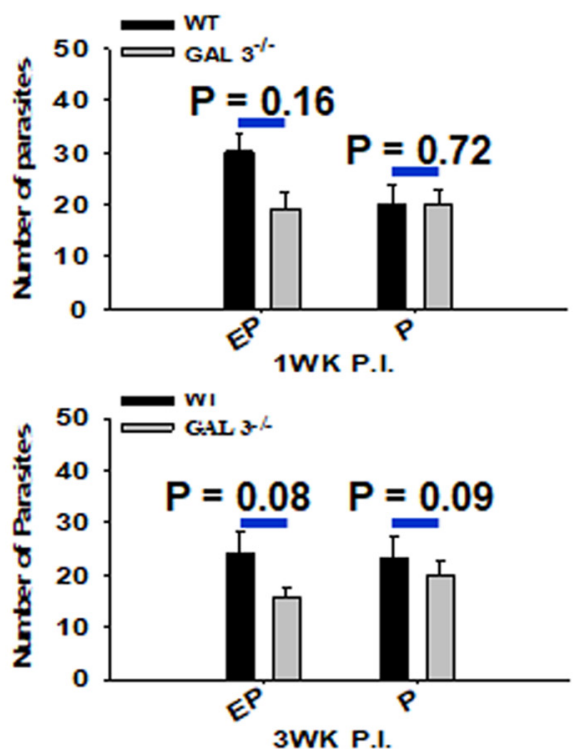

- WT
-. GAL $3^{-1-}$
C
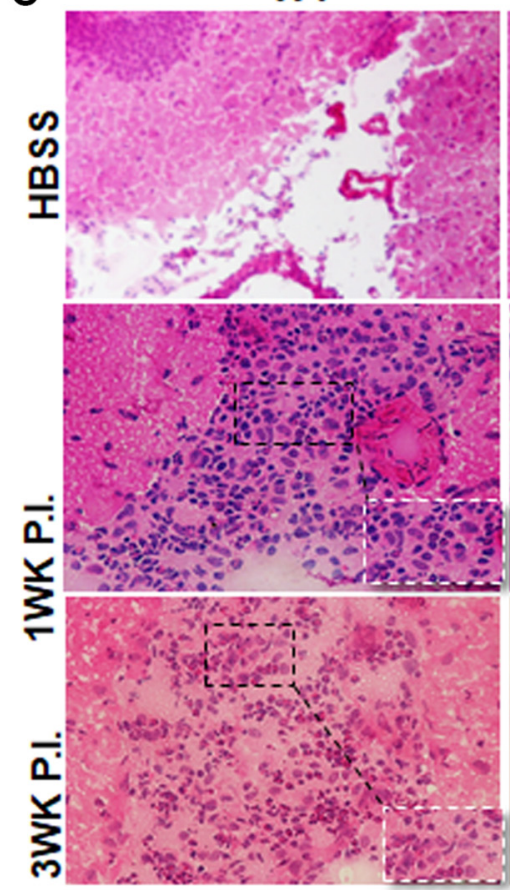

WT
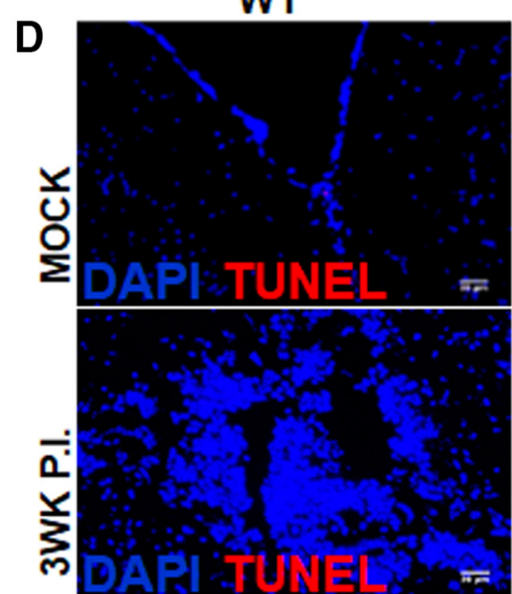

GAL $3^{-1-}$
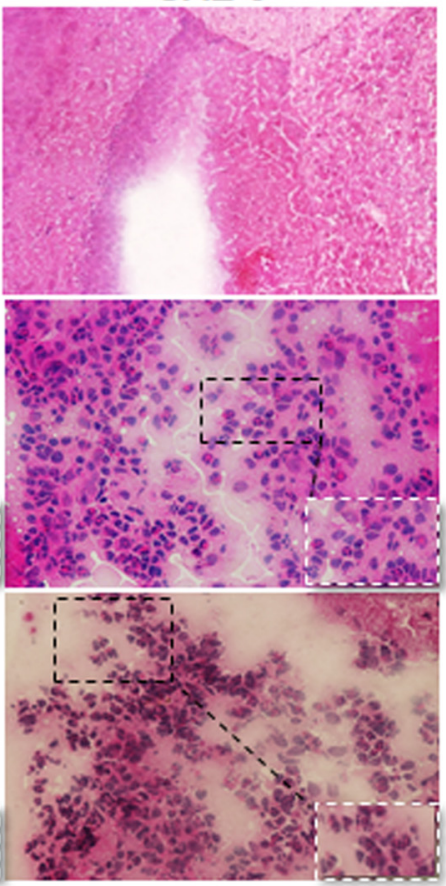

GAL $3^{-/-}$
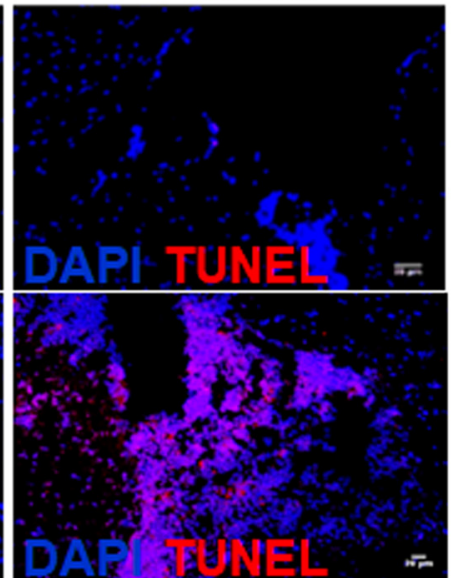

Figure 3. Galectin- $3^{-1-}$ mice exhibit reduced survival and increased brain pathology despite exhibiting similar parasite burden as the WT mice. $\boldsymbol{A}_{\text {, WT }}$ and Galectin-3 $3^{-/-}$mice were intracranially infected with $60 \mathrm{M}$. corti and were assessed daily for disease severity. The survival was monitored for 3 weeks after inoculation. Statistical comparison of susceptibility was done by Log-rank (Mantel-Cox) Test ( $n=9$ or 10). B, Number of parasites at 1 and 3 weeks after infection in whole-brain (WB), parenchymal (P), and extraparenchymal (EP) regions in individual Galectin- $3^{-1-}$ and WT brains were calculated by microscopic examination of serial H\&E-stained brain sections. Error bars indicate mean \pm SEM parasites from 5 or 6 mice per group. C, Representative microscopic evaluation of H\&E-stained brain cryosections from WT and Galectin-3 $3^{-1}$ mice intracranially injected with HBSS (mock) or with 60 parasites at indicated times after infection. Original magnification $\times 200$. D, IF microscopy analysis was performed on brain cryosections from WT and Galectin-3 $3^{-1-}$ mice intracranially infected with intracranially injected with HBSS (mock) or $60 \mathrm{M}$. corti parasites to detect TUNEL ${ }^{+}$staining (red). Nuclei (blue) were stained with DAPI. Images are representative of 5 or 6 mice in each group from three independent experiments.

Next, flow cytometry analysis was performed to enumerate immune cells infiltrating the CNS of Galectin- $3^{-1-}$ and WTinfected mice. Mononuclear cells from the whole brain were isolated at an early stage of infection ( 1 week after infection) and at the peak of inflammation (3 weeks after infection) (Figs. 5B, Fig. 6). The numbers of neutrophils in the CNS of Galectin- $3^{-1-}$ and WT infected mice were determined by quantifying $\mathrm{Ly}_{6 \mathrm{G}}{ }^{+} \mathrm{CD} 11 \mathrm{~b}^{+}$ cells. Consistent with the results from IF microscopy analysis, we found no significant differences in the percentage as well as absolute numbers of CD11b ${ }^{+} \mathrm{Ly}_{6 \mathrm{G}}{ }^{+}$neutrophils in the CNS of parasite-infected Galectin- $3^{-1-}$ mice compared with the WT at 1 week after infection (Fig. 5B). However, at 3 weeks after infection, the numbers of $\mathrm{Ly}_{6 \mathrm{G}}{ }^{+} \mathrm{CD} 11 \mathrm{~b}^{+}$neutrophils were significantly increased in the CNS of parasite-infected Galectin- $3^{-1-}$ mice compared with the WT mice (Fig. 5B), confirming that galectin-3 deficiency leads to increased accumulation of neutrophils in the CNS microenvironment during chronic infection. We found no significant differences in the numbers of dendritic cells $\left(\mathrm{CD} 11 \mathrm{c}^{+}\right)$, $\gamma \delta \mathrm{T}$ cells $\left(\mathrm{TCR} \delta^{+}\right), \alpha \beta$ T cells $\left(\mathrm{TCR} \beta^{+}\right)$, or B cells $\left(\mathrm{CD} 19^{+}\right)$at 1 or 3 weeks after infection CNS of Galectin- $3^{-/-}$and WT mice (data not shown). To determine whether the infiltration of M2 macrophages is affected in the absence of galectin-3, the number of 

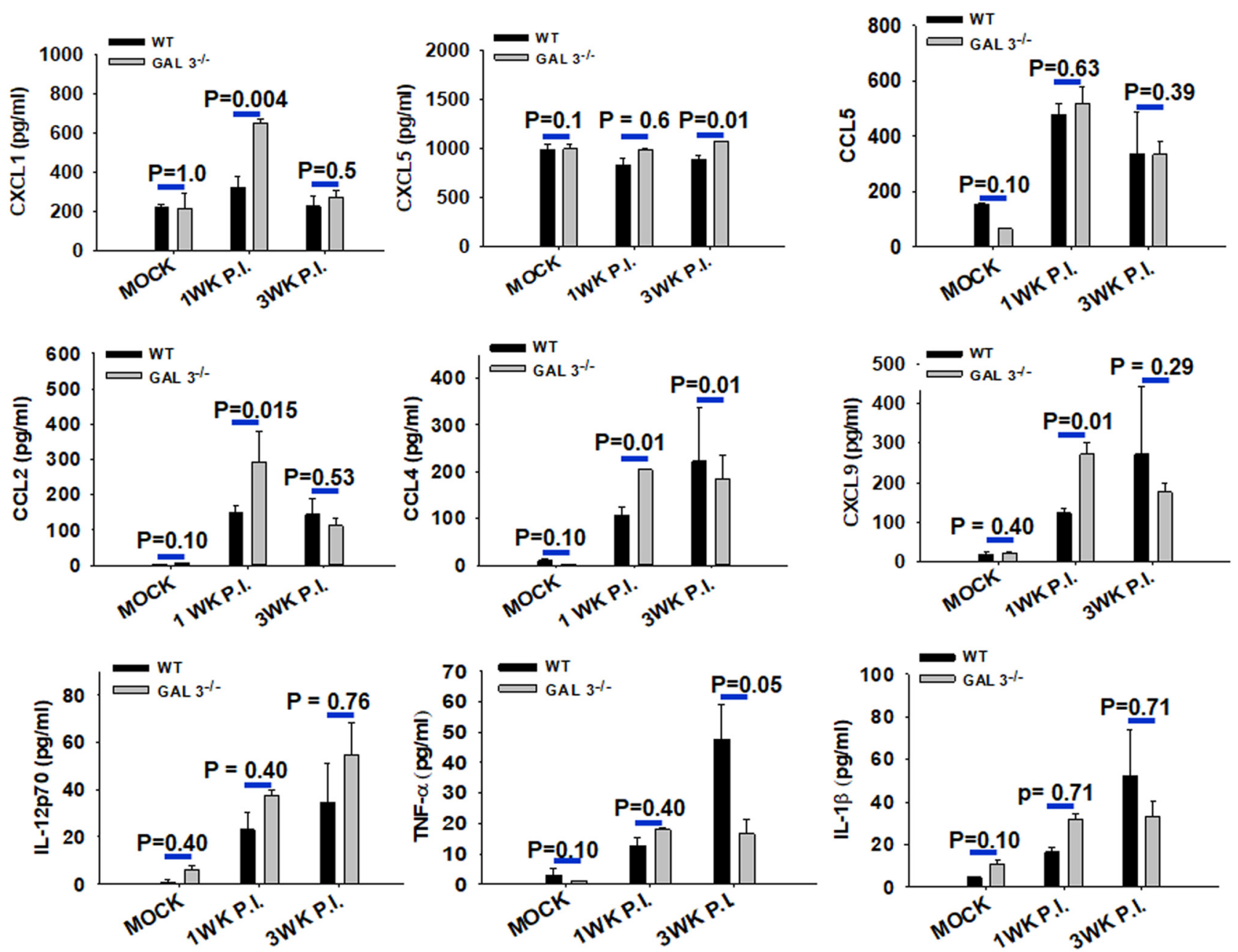

Figure 4. Inflammatory mediators in the CNS of parasite-infected Galectin- $3^{-/-}$and WT mice. The brains from mock control and $M$. corti-infected WT and Galectin-3 $3^{-1-}$ mice were harvested at 1 and 3 weeks after infection, homogenized, and the protein level of host immune mediators measured by CBA using flow cytometric analysis (BD Biosciences). Results shown are mean \pm SEM of 3 or 4 each infected and mock control mice from 2 or 3 independent experiments. Statistical significance ( $p$ values: $t$ test). $n=6$.

$\mathrm{MR}^{+}{ }^{+}$or PD-L2 ${ }^{+}$was enumerated as we previously have shown that MR1 is upregulated on M2 macrophages in parasite-infected brains whereas PD-L2 is a well-known marker of M2 cells (Mishra et al., 2011; Gundra et al., 2017). Indeed, CD45 ${ }^{\text {hi }} \mathrm{F} 4 / 80^{+} \mathrm{MR} 1^{+}$as well as $\mathrm{CD} 45^{\mathrm{hi}} \mathrm{F} 4 / 80^{+} \mathrm{PD}-\mathrm{L} 2{ }^{+} \mathrm{M} 2$ macrophages were detected at both higher percentage and numbers in the CNS of infected Galectin- $3^{-/-}$mice at 1 and 3 weeks after infection compared with their WT counterparts (Fig. 6A,B). This increased accumulation of M2 macrophages in the CNS of parasite-infected Galectin- $3^{-1-}$ mice was statistically significant. Together, our data suggested that galectin-3 in M2 macrophages likely plays a role in containment of neutrophilia in the CNS.

Adoptive transfer of M2 macrophage from WT mice reduces neutrophilia in the CNS and improves disease severity in recipient Galectin-3 $3^{-/-}$mice during brain parasitic infection Galectin-3 was found to be expressed primarily in infiltrating M2 macrophages in the CNS of $M$. corti intracranially infected mice. Because Galectin- $3^{-1-}$ NCC mice exhibited neutrophilia and severe disease signs, we sought to examine whether the adoptive transfer of galectin-3-sufficient M2 macrophages improves the disease severity. The effect on neutrophil turnover in the CNS and disease severity was compared in WT and Galectin- $3^{-/-}$mice after adoptive transfer of WT M2 macrophages. In initial exper- iments, macrophages were isolated from the brains of intracranially infected WT mice to use as donor cells. However, even though macrophages are the most predominant immuneinfiltrating cells found in the parasite-infected WT mouse brains, it was difficult to isolate sufficient numbers of these cells from the brain to perform adoptive transfer experiments in different groups. Thus, naive bone marrow-derived macrophages were Polarized to the M2 phenotype using well-characterized stimulus IL-4 for adoptive transfer experiments. M2 phenotype of these cells was verified by analyzing M2 markers Arginase- 1 and CCL24, but not NOS2 expression in these cells (data not shown). The M. corti intracranially infected WT and Galectin- $3^{-1-}$ NCC mice received vehicle or WT-M2 cells intravenously at 1 week, and 2 weeks after infection followed by analysis of neutrophils numbers in the CNS of recipients. Flow cytometry analysis revealed that the intravenously injected WT-M2 cells migrated into the CNS microenvironment of the recipient Galectin- $3^{-/-}$or WT mice with similar relative efficiency (Fig. 7-1, available at https://doi.org/ 10.1523/JNEUROSCI.3575-17.2018.f7-1). Indeed, 20\% of the CFSE-labeled WT-M2 cells $\left(\mathrm{F} 4 / 80{ }^{+} \mathrm{CFSE}^{+}\right)$injected intravenously migrated into the CNS of the infected recipient mice at $24 \mathrm{~h}$ after adoptive transfer (Fig. 7-1, available at https://doi.org/ 10.1523/JNEUROSCI.3575-17.2018.f7-1). In situ IF microscopy with anti-7/4 was performed on brain cryosections from recipi- 
A
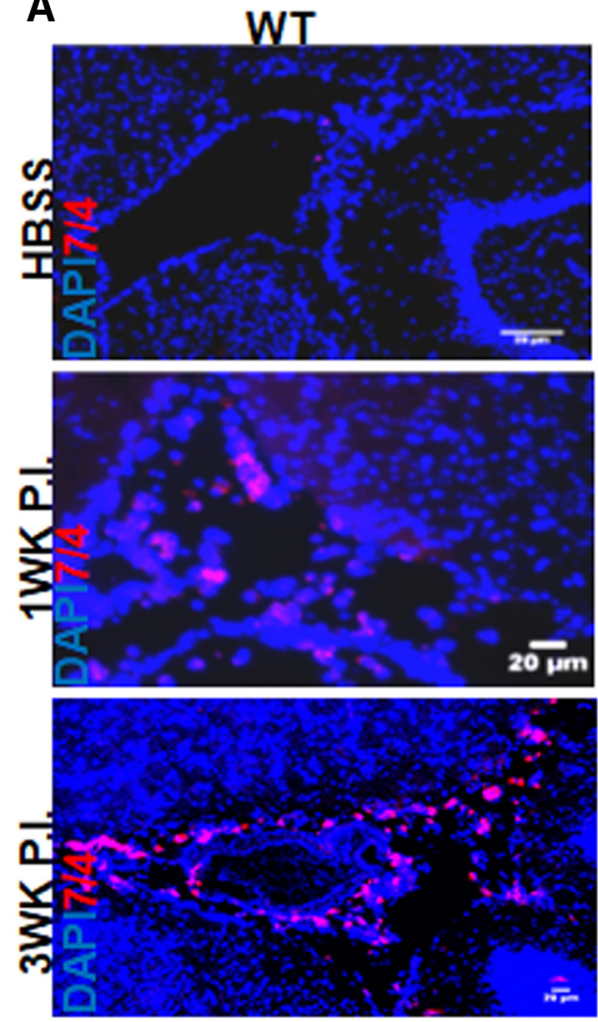

GAL $3-$
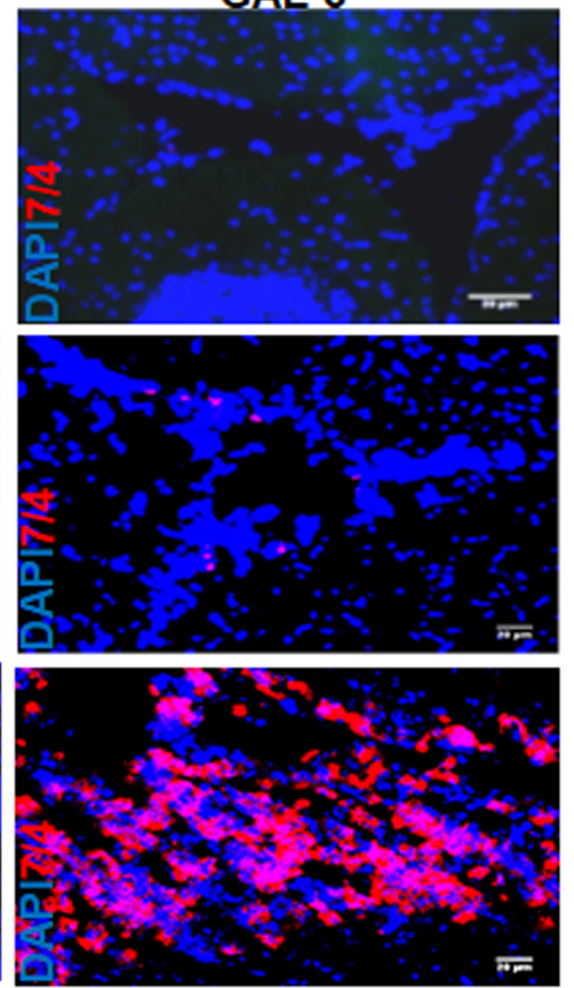

B
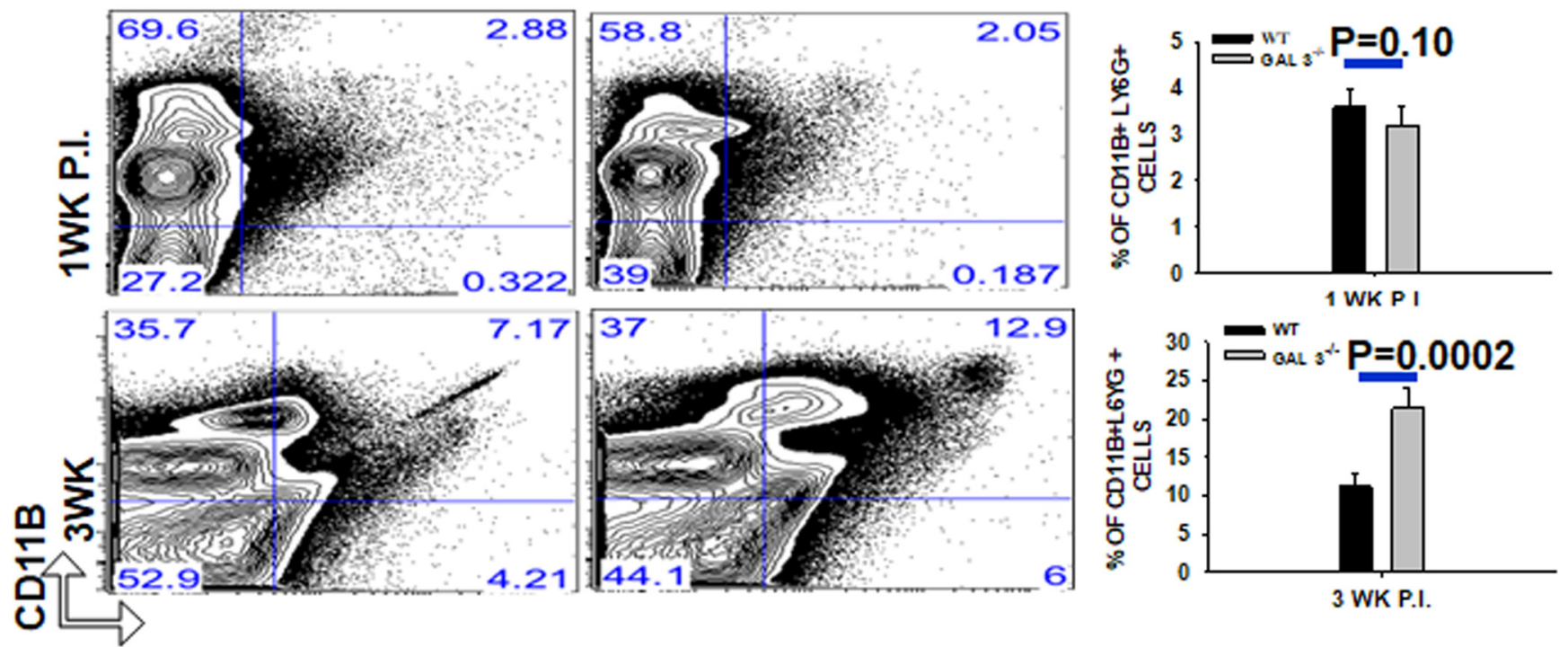

LY6G

Figure 5. Parasite-infected Galectin- $3^{-/-}$mice exhibit increased neutrophil accumulation in brain. A, IF microscopy on brain cryosections from WT and Galectin-3 ${ }^{-/-}$mice intracranially injected with HBSS (mock) or with 60 parasites at 1 and 3 weeks after infection. Neutrophils $(7 / 4+$ ) were detected by using an affinity purified anti-mouse $7 / 4$ goat lgG followed by AlexaFluor546-labeled (red). Nuclei (blue) were stained with DAPI. Images shown are representative of 3 independent experiments with 3 or 4 mice each group. B, Flow cytometry analysis of CD11b and Ly6G on brain mononuclear cells harvested from M. corti-infected WT and Galectin- $3^{-1-}$ mice at 1 and 3 weeks after infection. The cells were double-stained with anti-Ly6G-APC and anti-CD11b-Pacific Blue antibodies as markers for neutrophils. Representative contour plots show $\mathrm{CD} 11 \mathrm{~b}^{+} \mathrm{Ly} 6 \mathrm{G}{ }^{+}$neutrophils in brains of parasite-infected WT and Galectin- $3^{-1-}$ mice. Right, Bar graph represents mean \pm SEM of percentage of $C D 11 b^{+} \mathrm{Ly}_{6 G}{ }^{+}$neutrophils in brains of $M$. corti-infected WT and Galectin- $3^{-/-}$mice each from 3 independent experiments. Statistical significance $(n=6)$. $p$ values ( $t$ test).

ent mice at 3 weeks of NCC to detect the accumulation of neutrophils. Transfer of WT-M2 (experimental group: WT NCC-WT M2) or vehicle (experimental group: WT NCCVehicle) into the intracranially infected WT mice caused no apparent change in the number of $7 / 4+$ neutrophils accumulated in the CNS (Fig. 7B). On the other hand, infected Galectin- $3^{-1-}$ mice intravenously injected with vehicle (experimental group: Galectin- $3^{-1-}$ NCC-Vehicle) at 1 and 2 weeks after infection revealed the abundant presence of 7/4+ neutrophils in the CNS, which was substantially more compared with the experimental group: WT NCC-WT M2 (Fig. 7B). Importantly, transfer of WT M2 cells into intracranially infected Galectin- $3^{-/-}$mice (experi- 
A
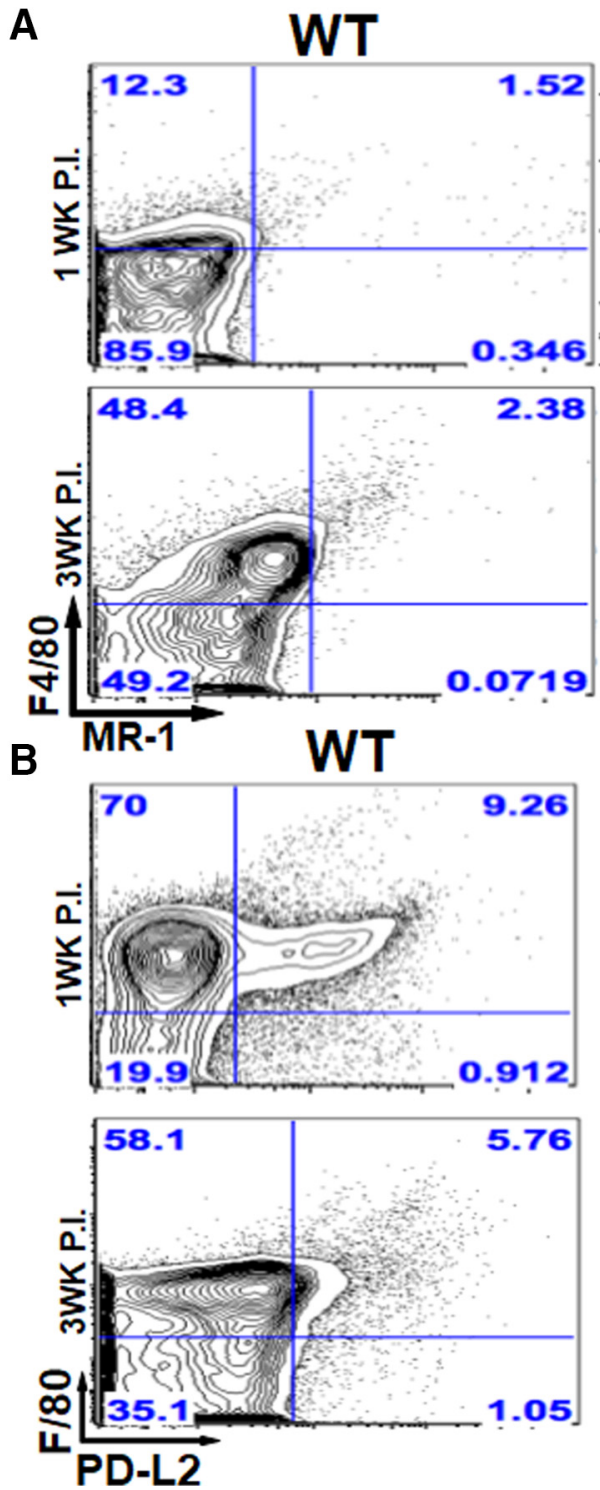

GAL 3\%
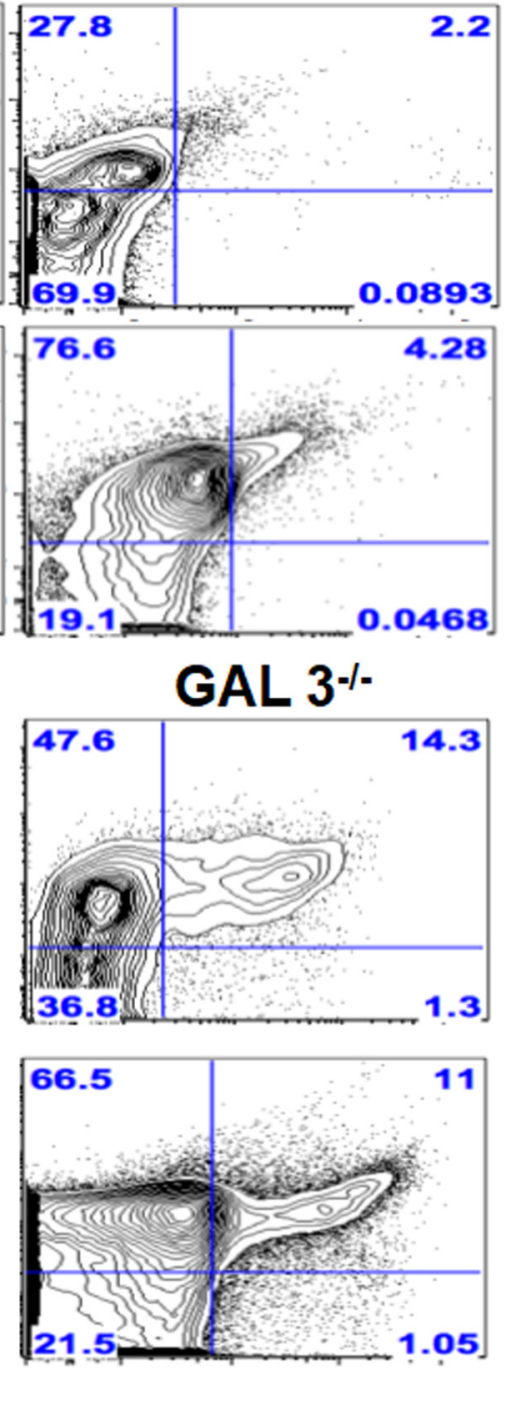
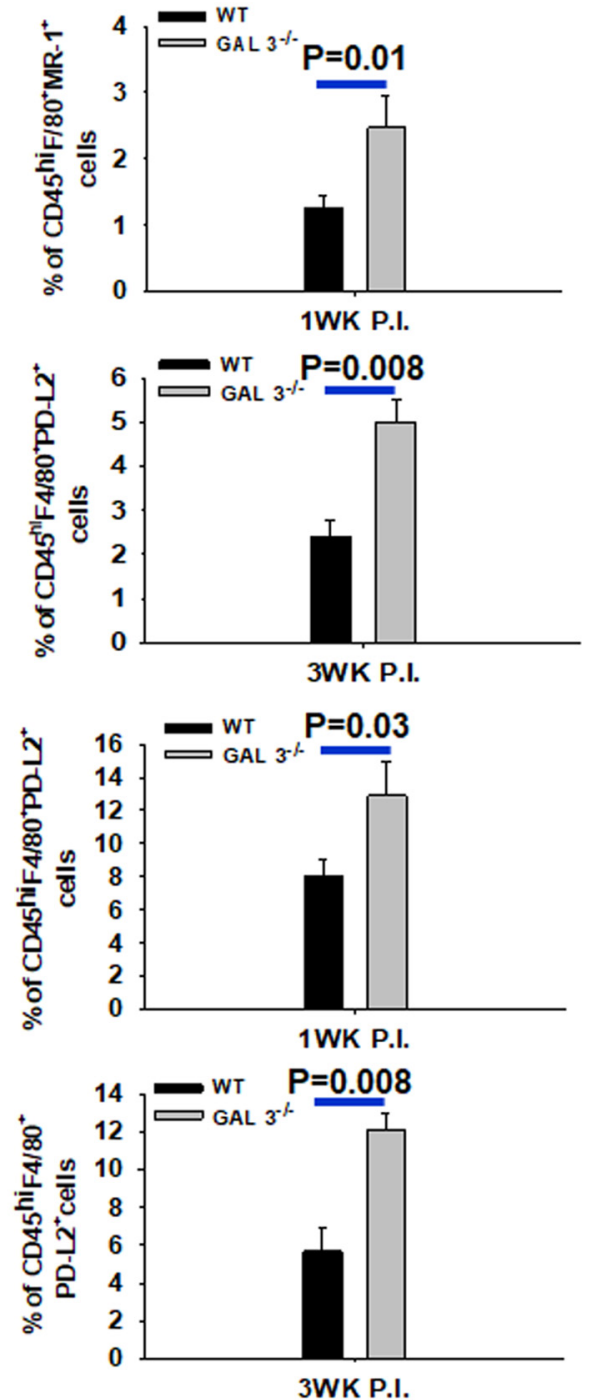

Figure 6. Parasite-infected Galectin- $3^{-/-}$mice exhibit increased M2 macrophages accumulation in brain. Brain mononuclear cells were harvested from $M$. corti-infected WT and Galectin-3 ${ }^{-/-}$ mice at 1 and 3 weeks after infection. Cells were costained with anti-CD45-Pacific Blue, anti-F4/80-PE-cy7, along with anti-MR-1-APC or anti-PD-L2-PE. A, Representative scatter plots showing percentage of $\mathrm{CD} 45^{\mathrm{hi}} \mathrm{F} 4 / 80^{+} \mathrm{MR} 1{ }^{+} \mathrm{M} 2$ macrophages at 1 and 3 week postinfected brains. Bar graph represents the average $\pm \mathrm{SEM}$ from 3 mice per group in 3 independent experiments. Statistical significance. $\boldsymbol{B}$, Representative scatter plots showing percentage of $\mathrm{CD} 45^{\text {hi }} \mathrm{F} 4 / 80^{+} \mathrm{PDL}-2^{+} \mathrm{M} 2$ macrophages at 1 and 3 week postinfected brains. Bar graph represents the average $\pm \mathrm{SEM}$ from 3 mice per group in 3 independent experiments. Statistical significance ( $p$ values: $t$ test).

mental group: Galectin-3 $3^{-/}$NCC- WT M2) resulted in a significant decrease in the number of $7 / 4+$ neutrophils accumulated in the CNS compared with the Galectin- $3^{-1-}$ NCC mice that received vehicle only (Fig. $7 B$ ). These results confirmed that Galectin-3-expressing M2 macrophages regulate neutrophilia in the CNS during brain parasitic infection.

To determine whether adoptive transfer of galectin-3-sufficient WT-M2 cells would prevent disease severity in Galectin- $3^{-1-}$ NCC mice, WT and Galectin- $3^{-1-}$ mice inoculated intracranially with $M$. corti were intravenously injected with vehicle or WT M2 cells at 1 week, and 2 weeks after infection as discussed above. WT NCC-Vehicle displayed typical neurological signs (abnormal vestibular function, tilted head, and cerebral abnormalities) by 3 weeks after infection. These infection-induced disease signs appeared earlier and were more pronounced in Galectin-3 $3^{-1-}$ NCC-vehicle group of mice. In addition, these Galectin- $3^{-1-}$ NCC mice that received vehicle exhibited decreased survival (Fig. $7 C$ ).
By $26 \mathrm{~d}$ after infection, 25\% of $M$. corti-infected WT mice succumbed to the infection compared with $80 \%$ of Galectin- $3^{-1-}$ mice ( 4 of 5 ) (Fig. 1, $p<0.005$ ). In contrast, none of the Galectin- $3^{-/-}$NCC-WT M2 mice exhibited severe neurological signs during the 3 weeks after infection and all survived the infection. These data strongly showed that adoptive transfer of Galectin-3-sufficient M2 macrophages ameliorated disease severity and improved survival during CNS parasite infection in Galectin-3 $3^{-1-}$ mice.

\section{Galectin-3 $^{-/-}$M2 macrophages exhibit impaired}

efferocytosis of neutrophils

A prominent anti-inflammatory and tissue-reparative function of M2 macrophages is efferocytic clearance of infiltrating immune cells (Bystrom et al., 2008; Mosser and Edwards, 2008; FernandezBoyanapalli et al., 2010; David and Kroner, 2011). To gain mechanistic insights into the role of Galectin-3 expressed in M2 
A

\section{Vehicle \\ or \\ WT M2}

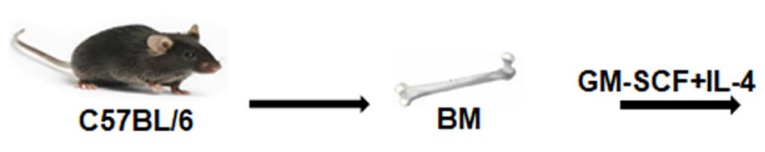

B
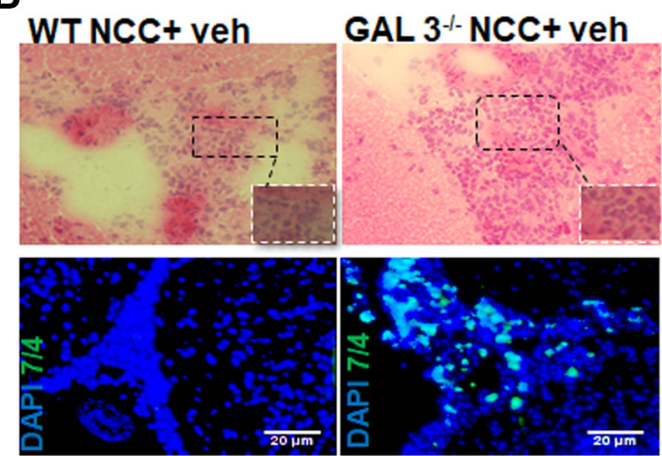

GAL $3^{-1-} \mathrm{NCC}+$ veh

\section{C}
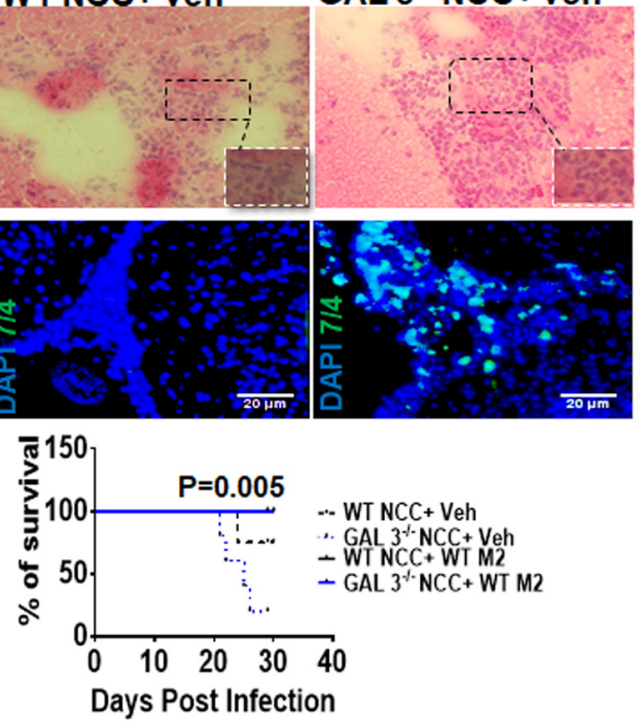
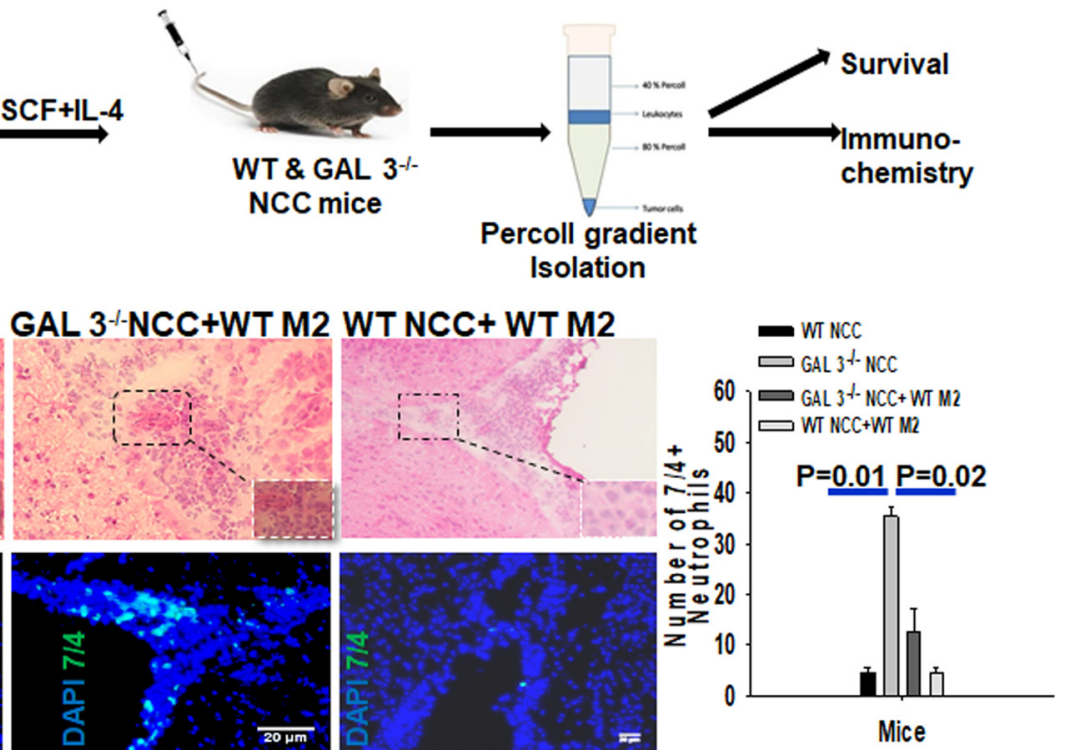

Figure 7. Galectin-3-expressing M2 macrophages exhibit protective role during NCC infection. $\boldsymbol{A}$, Schematic representation of the adoptive transfer experiment as described in Materials and Methods. Purified bone marrow macrophages from WT mice were differentiated to M2 phenotype (WT M2) by exposure to IL-4 in vitro. WT (WT NCC) or Galectin-3 ${ }^{-1-}$ (GAL3 ${ }^{-} / \mathrm{NCC}$ mice, undergoing NCC due to intracranial infection with M. corti, received WT M2 (WT NCC + WT M2; GAL3 ${ }^{-1-}$ NCC + WT M2) or vehicle (WT NCC + Veh; GAL3 ${ }^{-} / N C C+$ Veh) at 1 and 2 weeks after infection Disease severity among these four groups was compared at 3 weeks of NCC. $\boldsymbol{B}$, Top, Representative images of H\&E-stained brain cryosections. Bottom, IF microscopy images of brain cryosections to compare accumulation of $7 / 4+$ (green) neutrophils. Nuclei (blue) were stained with DAPI. Bar graph represents 7/4+ neutrophils manually counted from images shown at bottom from 3 independent experiments with 3 mice per experiment. $p$ values ( $t$ test). C, The survival of WT NCC and Galectin- $3^{-/-}$NCC mice adoptively transferred with WT-M2 macrophages or vehicle was monitored for 3 weeks. Statistical significance was determined by Student's $t$ test. $p$ values ( $t$ test and Log-rank [Mantel-Cox] Test). Migration of CFSE-labeled WT-M2 cells (F4/80 ${ }^{+}$CFSE ${ }^{+}$) into the CNS of the recipient WT and Galectin-3 ${ }^{-1-}$ NCC mice at $24 \mathrm{~h}$ postadoptive intravenous transfer is presented in Figure 7-1 (available at https://doi.org/10.1523/JNEUROSCI.3575-17.2018.f7-1).

macrophages in regulating neutrophil accumulation in helminth-infected brains, we compared ex vivo efferocytosis of CFSE-labeled neutrophils by M2 macrophages from WT and Galectin- $3^{-/-}$mice by flow cytometry (Fig. 8). For this, Galectin- $3^{-/-}$and WT peritoneal M2 macrophages isolated from the $M$. corti intraperitoneally infected (Fig. 8B) or thioglycollate+IL-4 complex intraperitoneally injected mice (Fig. 8C) were incubated with CFSE-labeled neutrophils. M2 phenotype of macrophages was ensured by flow cytometry analysis of differential expression of M1/M2 markers PD-L2, MR-1, ARG-1, and NOS2, as described above (Fig. 8-1, available at https://doi.org/10.1523/JNEUROSCI.3575-17.2018.f8-1; and data not shown). As shown in Figure $8 B, B^{\prime}$, after $3 \mathrm{~h}$ of incubation, efferocytic uptake of CFSE-labeled neutrophils was significantly less in Galectin-3 $3^{-/-}$M2 macrophages compared with their WT counterparts. Similar results were obtained with WT and Galectin-3 $3^{-1-}$ M2 macrophages differentiated with peritoneal injection of IL-4 complex (Fig. $8 C, C^{\prime}$ ). These data strongly suggested that galectin-3 expression in M2 macrophages is required for efferocytic uptake of neutrophils by these cells.

\section{Discussion}

Increasing evidence from several experimental neuropathological models, such as in traumatic brain injury, suggests that M2 macrophages are the first to infiltrate into CNS tissues (David and Kroner, 2011; Wang et al., 2013). As the injury persists, a shift to increased accumulation of M1 phenotypic macrophages in the CNS coincides with the inflammatory pathologic phase (Nakagawa and Chiba, 2015). Whereas regulatory immune mediators, such as IL-10 and TGF- $\beta$, have been implicated in M2 cellmediated immune suppression/anti-inflammatory response, important central regulatory mechanisms involved in M2 macrophage functions to contain CNS inflammation and pathology need to be identified. The data presented here show that, during brain helminth infection of the CNS, cytosolic galectin-3 is increased specifically in M2 macrophages, but not substantially in microglia. Concomitantly, the absence of galectin-3 resulted in a massive increase in the accumulation of neutrophils correlating with heightened disease severity in $M$. corti-infected Galectin- $3^{-/-}$mice compared with WT mice. Galectin-3 deficiency in M2 macrophages decreased efferocytic clearance of neutrophils by these cells. Importantly, pathological sequelae, including severe neutrophilia in CNS parasite-infected Galectin-3 $3^{-/-}$mice, were ameliorated by adoptive transfer of Galectin-3-sufficient M2 macrophages. Our study shows, for the first time, a protective role of M2 macrophage-associated galectin-3 in brain parasitic infection by controlling neutrophil turnover in the CNS. 
A
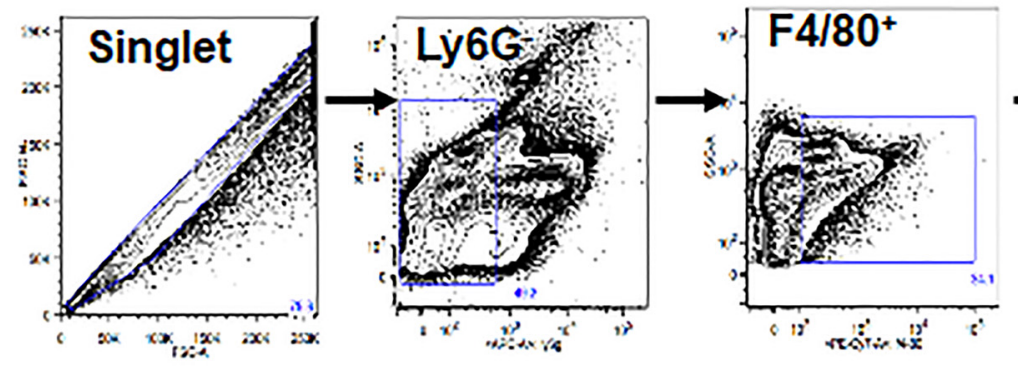

\section{$\rightarrow$ CFSE $^{+}$cells}

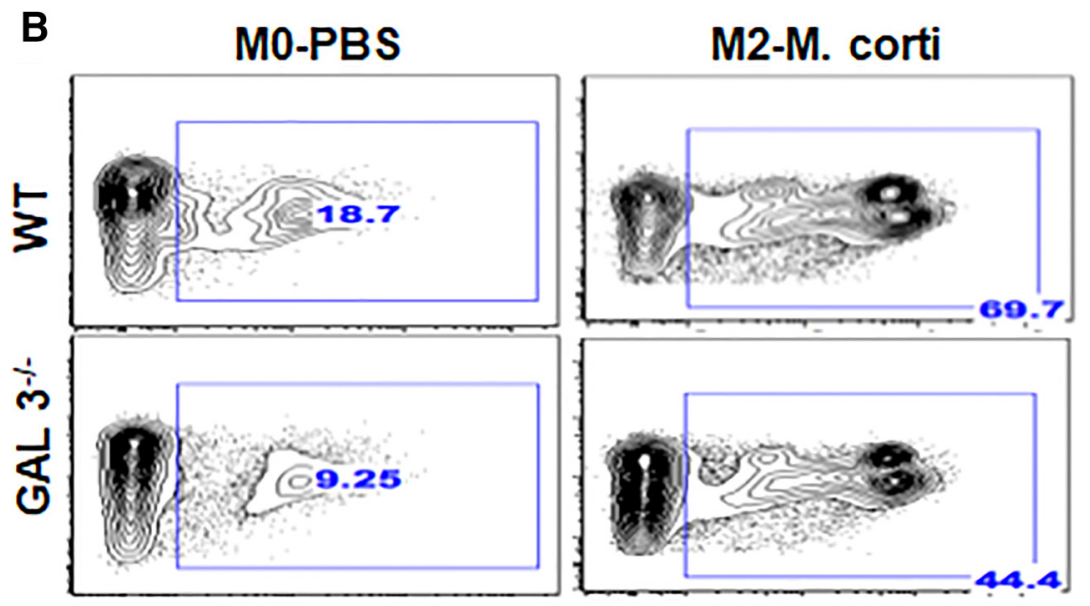

B'

\section{LY6G-F4/80+CFSE ${ }^{+}$}

C
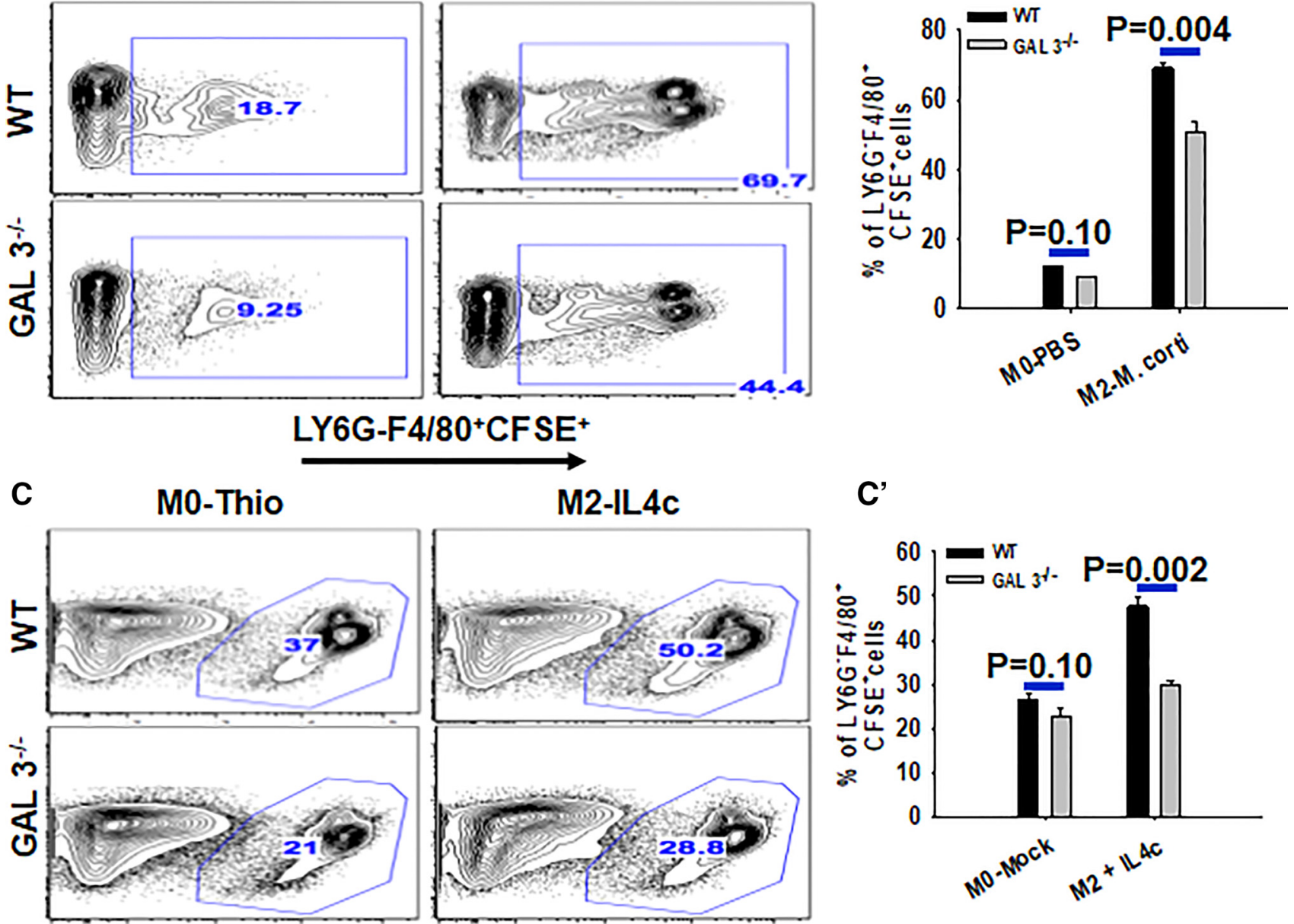

\section{LY6G-F4/80+CFSE ${ }^{+}$}

Figure 8. Galectin- $3^{-/-} \mathrm{M} 2$ macrophages exhibit reduced efferocytosis of neutrophils ex vivo. A, Gating scheme to select efferocytic cells and singlet cells gated on FSC-H and FSC-A and the Ly6G-negative to eliminate untaken neutrophils that may be on the surface of macrophages and $\mathrm{CFSE}^{+}$to quantify the macrophages that internalized the neutrophils (Ly6G ${ }^{-} \mathrm{F} 4 / 80^{+} \mathrm{CFSE}^{+}$cells) (B). Efferocytosis of CFSE ${ }^{+}$neutrophils by macrophages from WT and Galectin- $3^{-/-}$mock control mice that received vehicle (M0-PBS) or M. corti parasite (M2 M. corti) intraperitoneally. $\boldsymbol{B}^{\prime}$, Bar graph represents the percentage of $\mathrm{Ly}_{6 \mathrm{G}}{ }^{-} \mathrm{F} 4 / 80^{+}{ }^{+} \mathrm{CFSE}{ }^{+}$macrophages that have internalized CFSE-labeled neutrophils calculated from 3 independent experiments that are shown in the representative density plots (B). C, Macrophages from WT and Galectin- $3^{-1-}$ mock control mice that intraperitoneally received vehicle (MO-Thio) or IL4 complex (M2 IL4C) were analyzed for efferocytosis of CFSE-labeled neutrophils. $C^{\prime}$, Bar graph represents the percentage of $\mathrm{Ly}_{6 \mathrm{G}}{ }^{-} \mathrm{F} 4 / 80^{+} \mathrm{CFSE}{ }^{+}$macrophages that have internalized CFSE-labeled neutrophils calculated from 3 independent experiments that are shown in the representative density plots (C). Statistical significance was determined by Student's $t$ test. $p$ values ( $t$ test). Data presented in Figure 8-1 (available at https://doi.org/10.1523/JNEUROSCI.3575-17.2018.f8-1) show that macrophages in the peritoneal exudate during M. corti infection express M2-, but not M1-phenotypic, immune mediators.

There has been a growing appreciation for a role of macrophage/microglia with M2 functional phenotype having a profound role in different aspects of CNS repair and containment of immunopathology in the brain (Hu et al., 2015). Indeed, results from our previous studies with STAT6 ${ }^{-1-}$ or TLR2 ${ }^{-1-}$ mice provide direct evidence for the critical protective role of the myeloid cells with M2 functional phenotype in the brain microenvironment, during CNS parasite infection (Mishra et al., 2009; Gundra 
et al., 2011). Here we observed that the parasite-infected Galectin- $3^{-/-}$mice, despite showing the presence of an increased number of M2 macrophages in the CNS compared with their WT counterparts, exhibit severe neurological signs and are highly susceptible to the infection. In the CNS of Galectin $-3^{-/-}$mice, perhaps the observed elevated amount of the chemokines, including CCL2, which are known to involve in trafficking of monocytes/ macrophages (Ransohoff et al., 2003; Shi and Pamer, 2011), facilitates the increased influx of M2 cells. This indicated to us that the protective function, but not the development, of M2 cells is dependent on galectin-3. Indeed, in the parasite-infected brains, galectin-3 was primarily detected in infiltrating M2 macrophages, and the transfer of Galectin-3-sufficient M2 macrophage from WT mice reversed the infection-induced CNS pathology and improved the survival of parasite-infected Galectin- $3^{-1-}$ mice. These results highlight the importance of galectin-3 in M2 macrophagemediated protective functions to contain CNS pathological processes. However, it remains to be determined the consequence as well as the mechanisms involved in the increased accumulation of M2 macrophages in the CNS of parasite-infected Galectin- $3^{-/-}$ mice. In this regard, it has been suggested that galectins, including galectin-3, can play a role in immune cell trafficking (Sperandio et al., 2009; Ge et al., 2013; Jia et al., 2013). However, our results showed that adoptively transferred galectin-3-sufficient as well as -deficient M2 macrophages accumulated in the CNS of both WT and Galectin- $3^{-1-}$ mice with similar frequency. This strongly supports the idea that the enhanced disease severity in Galectin- $3^{-1-}$ NCC mice was a direct consequence of a lack of the galectin-3-mediated response from $\mathrm{M} 2$ cells, but not due to a defect in M2 macrophage development or trafficking (MacKinnon et al., 2008; Jia et al., 2013).

In $M$. corti-infected WT mice brains, neutrophils were detected as a minor proportion of the immune cells present in the brain of M. corti-infected WT mice. Earlier studies have also identified similar low numbers of neutrophils in the CNS microenvironment during murine NCC (Cardona et al., 1999). However, infected brains in Galectin- $3^{-1-}$ mice display a massive increase in the number of neutrophils compared with the WT mice, suggesting a role for galectin-3 in regulating neutrophil turnover. The transfer of M2 macrophage from WT could reverse this increase of neutrophil accumulation in the CNS microenvironment of $M$. corti-infected Galectin- $3^{-1-}$ mice, thus providing additional support for a role of galectin-3 in M2 macrophagemediated containment of neutrophilia. In this regard, lower numbers of immune cells have been observed to extravasate through parenchymal vessels than the pial vessels until 5 weeks after infection in this model (Alvarez and Teale, 2006). This, coupled with our results showing detection of TUNEL ${ }^{+}$cells primarily in extraparenchyma in Galectin- $3^{-/-}$mice, leads us to speculate that the observed galectin-3-mediated M2 macrophage function in containment of neutrophilia occurred at the meninges. On the other hand, as galectin-3 played a role in peritoneal M2 macrophage-mediated efferocytosis of neutrophils, we anticipate it to play a similar role in parenchymal M2 macrophagemediated function in chronic CNS disease conditions. Nevertheless, the observation that the increase of neutrophil accumulation in the CNS microenvironment of $M$. corti-infected Galectin- $3^{-1-}$ mice is exciting, as the absence of M2 macrophages has been shown to associate with increased neutrophilia and reduced eosinophilia during infection with a nematode parasite, Brugia malayi, but the mechanism remained unknown (Loke et al., 2007). Indeed, in $M$. cort $i$ intraperitoneally infected Galectin- $3^{-/-}$mice, we observed a reduced eosinophilia coinciding with the increased neutrophilia (data not shown) further supporting a fundamental role of M2 macrophage-associated functions of galectin-3 in controlling neutrophilia. Although the molecular pathway of galectin-3mediated containment of neutrophilia in the CNS microenvironment remains to be determined, our data showing a defect in efferocytosis of neutrophils by Galectin- $3^{-1-} \mathrm{M} 2$ macrophages in vitro suggests its regulatory role in efferocytic ability of these cells. In this context, a recent report has suggested that galectin-3 expressed and secreted by neutrophils autoregulate their turnover during a self-resolving model of peritonitis with zymosan injection (Wright et al., 2017). It has further been suggested that galectin-3 secreted by neutrophils facilitates efferocytosis of these cells by interacting with its ligand on macrophage surface $(\mathrm{Mu}-$ karo et al., 2013). However, the data from our studies clearly suggested a cytosolic, but not extracellular, presence of galectin-3 in M2 macrophages in parasite-infected brains. Moreover, if secreted galectin-3 was involved in containing neutrophilia in parasite-infected brain, we would expect to detect galectin-3 on the surface of macrophages and/or neutrophils, which was not the case. Thus, galectin-3 in M2 macrophages regulates neutrophil turnover by efferocytosis in the CNS microenvironment. Mechanistically how cytosolic galectin-3 regulates neutrophil efferocytosis by M2 macrophages needs to be identified. One possibility is that internalization of apoptotic cells requires macrophages to dynamically reorganize their actin cytoskeleton to drive F-actin formation around apoptotic cells, forming a socalled phagocytic cup, which then promotes mechanical retraction of the phagosome into the cell (Yurdagul et al., 2017). Perhaps galectin-3 plays a role on cytoskeleton rearrangement (Sano et al., 2003) in M2 macrophages to facilitate efferocytosis of neutrophils, a hypothesis we are currently testing in our laboratory.

The findings that several signature inflammatory mediators are present at a similar level in the CNS Galectin- $3^{-1-}$ mice despite exhibiting low survival raised the fundamental question of whether M2 subsets are sufficient to contain NCC and other CNS pathological conditions. Indeed, in human NCC patients, the hyperinflammatory responses in the CNS thought to contribute to tissue pathology and mortality (Nash et al., 2006). Thus, along with antiparasitic drugs, treatment of NCC patients with immunosuppressive/anti-inflammatory factors, such as corticosteroids, is frequently used to control the associated neuropathology, despite the life-threatening side effects associated with long-term treatments with steroids (White, 1997). Within that context, we and others have shown that a decreased expression of the inflammatory mediators in M. corti-infected $\gamma \delta T^{-/-}$or $M y D 88^{-/-}$mice is associated with reduced pathology and longer survival times. But despite the presence of lower brain levels of these inflammatory mediators, $M$. corti-infected TLR2 ${ }^{-1-}$ mice presented an increased CNS pathology and disease signs (Gundra et al., 2011). We have also shown that the reduced numbers of M2 macrophages observed in TLR $2^{-1-}$ mice, and more importantly in the CNS of STAT6 ${ }^{-1-}$ mice, coincided with severe disease signs in murine NCC (Mishra et al., 2011). Thus, the findings from these studies that galectin-3 can profoundly influence M2 macrophage cell functions in the CNS may be directly relevant to human disease notably involving CNS pathological conditions.

\section{References}

Alvarez JI, Mishra BB, Gundra UM, Mishra PK, Teale JM (2010a) Mesocestoides corti intracranial infection as a murine model for neurocysticercosis. Parasitology 137:359-372. CrossRef Medline

Alvarez JI, Mishra BB, Gundra UM, Mishra PK, Teale JM (2010b) Mesocestoides corti intracranial infection as a murine model for neurocysticercosis. Parasitology 137:359-372. CrossRef Medline 
Alvarez JI, Rivera J, Teale JM (2008) Differential release and phagocytosis of tegument glycoconjugates in neurocysticercosis: implications for immune evasion strategies. PLoS Negl Trop Dis 2:e218. CrossRef Medline

Alvarez JI, Teale JM (2006) Breakdown of the blood brain barrier and blood-cerebrospinal fluid barrier is associated with differential leukocyte migration in distinct compartments of the CNS during the course of murine NCC. J Neuroimmunol 173:45-55. CrossRef Medline

Bystrom J, Evans I, Newson J, Stables M, Toor I, van Rooijen N, Crawford M, Colville-Nash P, Farrow S, Gilroy DW (2008) Resolution-phase macrophages possess a unique inflammatory phenotype that is controlled by cAMP. Blood 112:4117-4127. CrossRef Medline

Cardona AE, Restrepo BI, Jaramillo JM, Teale JM (1999) Development of an animal model for neurocysticercosis: immune response in the central nervous system is characterized by a predominance of gamma $\delta \mathrm{T}$ cells. J Immunol 162:995-1002. Medline

Chauhan A, Sun Y, Pani B, Quenumzangbe F, Sharma J, Singh BB, Mishra BB (2014) Helminth induced suppression of macrophage activation is correlated with inhibition of calcium channel activity. PLoS One 9:e101023. CrossRef Medline

Cooper DN (2002) Galectinomics: finding themes in complexity. Biochim Biophys Acta 1572:209-231. CrossRef Medline

Cooper D, Iqbal AJ, Gittens BR, Cervone C, Perretti M (2012) The effect of galectins on leukocyte trafficking in inflammation: sweet or sour? Ann N Y Acad Sci 1253:181-192. CrossRef Medline

David S, Kroner A (2011) Repertoire of microglial and macrophage responses after spinal cord injury. Nat Rev Neurosci 12:388-399. CrossRef Medline

Dell A, Haslam SM, Morris HR, Khoo KH (1999) Immunogenic glycoconjugates implicated in parasitic nematode diseases. Biochim Biophys Acta 1455:353-362. CrossRef Medline

Fernandez-Boyanapalli R, Frasch SC, Riches DW, Vandivier RW, Henson PM, Bratton DL (2010) PPARgamma activation normalizes resolution of acute sterile inflammation in murine chronic granulomatous disease. Blood 116:4512-4522. CrossRef Medline

Franco R, Fernandez-Suarez D (2015) Alternatively activated microglia and macrophages in the central nervous system. Progress in neurobiology 131:65-86. CrossRef Medline

Ge XN, Ha SG, Liu FT, Rao SP, Sriramarao P (2013) Eosinophil-expressed galectin-3 regulates cell trafficking and migration. Front Pharmacol 4:37. CrossRef Medline

Girgis NM, Gundra UM, Loke P (2013) Immune regulation during helminth infections. PLoS Pathog 9:e1003250. CrossRef Medline

Girgis NM, Gundra UM, Ward LN, Cabrera M, Frevert U, Loke P (2014) Ly6C(high) monocytes become alternatively activated macrophages in schistosome granulomas with help from $\mathrm{CD}^{+}{ }^{+}$cells. PLoS Pathog 10: e1004080. CrossRef Medline

Glass CK, Natoli G (2016) Molecular control of activation and priming in macrophages. Nat Immunol 17:26-33. CrossRef Medline

Gundra UM, Mishra BB, Wong K, Teale JM (2011) Increased disease severity of parasite-infected TLR $2^{-1-}$ mice is correlated with decreased central nervous system inflammation and reduced numbers of cells with alternatively activated macrophage phenotypes in a murine model of neurocysticercosis. Infect Immun 79:2586-2596. CrossRef Medline

Gundra UM, Girgis NM, Rückerl D, Jenkins S, Ward LN, Kurtz ZD, Wiens KE, Tang MS, Basu-Roy U, Mansukhani A, Allen JE, Loke P (2014) Alternatively activated macrophages derived from monocytes and tissue macrophages are phenotypically and functionally distinct. Blood 123: e110-e122. CrossRef Medline

Gundra UM, Girgis NM, Gonzalez MA, San Tang M, Van Der Zande HJ, Lin JD, Ouimet M, Ma LJ, Poles J, Vozhilla N, Fisher EA, Moore KJ, Loke P (2017) Vitamin A mediates conversion of monocyte-derived macrophages into tissue-resident macrophages during alternative activation. Nat Immunol 18:642-653. CrossRef Medline

Hu X, Li P, Guo Y, Wang H, Leak RK, Chen S, Gao Y, Chen J (2012) Microglia/macrophage polarization dynamics reveal novel mechanism of injury expansion after focal cerebral ischemia. Stroke 43:3063-3070. CrossRef Medline

Hu X, Leak RK, Shi Y, Suenaga J, Gao Y, Zheng P, Chen J (2015) Microglial and macrophage polarization-new prospects for brain repair. Nat Rev Neurol 11:56-64. CrossRef Medline

Jia W, Kidoya H, Yamakawa D, Naito H, Takakura N (2013) Galectin-3 accelerates M2 macrophage infiltration and angiogenesis in tumors. Am J Pathol 182:1821-1831. CrossRef Medline

Jondle CN, Sharma A, Simonson TJ, Larson B, Mishra BB, Sharma J (2016) Macrophage galactose-type lectin-1 deficiency is associated with increased neutrophilia and hyperinflammation in gram-negative pneumonia. J Immunol 196:3088-3096. CrossRef Medline

Leffler H, Carlsson S, Hedlund M, Qian Y, Poirier F (2002) Introduction to galectins. Glycoconj J 19:433-440. CrossRef Medline

Locati M, Mantovani A, Sica A (2013) Macrophage activation and polarization as an adaptive component of innate immunity. Adv Immunol 120: 163-184. CrossRef Medline

Loke P, Gallagher I, Nair MG, Zang X, Brombacher F, Mohrs M, Allison JP, Allen JE (2007) Alternative activation is an innate response to injury that requires $\mathrm{CD}^{+} \mathrm{T}$ cells to be sustained during chronic infection. J Immunol 179:3926-3936. CrossRef Medline

MacKinnon AC, Farnworth SL, Hodkinson PS, Henderson NC, Atkinson KM, Leffler H, Nilsson UJ, Haslett C, Forbes SJ, Sethi T (2008) Regulation of alternative macrophage activation by galectin-3. J Immunol 180: 2650-2658. CrossRef Medline

Mahanty S, Garcia HH (2010) Cysticercosis and neurocysticercosis as pathogens affecting the nervous system. Prog Neurobiol 91:172-184. CrossRef Medline

Miron VE, Boyd A, Zhao JW, Yuen TJ, Ruckh JM, Shadrach JL, van Wijngaarden P, Wagers AJ, Williams A, Franklin RJM, ffrench-Constant C (2013) M2 microglia and macrophages drive oligodendrocyte differentiation during CNS remyelination. Nat Neurosci 16:1211-1218. CrossRef Medline

Mishra BB, Mishra PK, Teale JM (2006) Expression and distribution of tolllike receptors in the brain during murine neurocysticercosis. J Neuroimmunol 181:46-56. CrossRef Medline

Mishra BB, Gundra UM, Teale JM (2008) Expression and distribution of toll-like receptors 11-13 in the brain during murine neurocysticercosis. J Neuroinflammation 5:53. CrossRef Medline

Mishra BB, Gundra UM, Wong K, Teale JM (2009) MyD88-deficient mice exhibit decreased parasite-induced immune responses but reduced disease severity in a murine model of neurocysticercosis. Infect Immun 77: 5369-5379. CrossRef Medline

Mishra BB, Gundra UM, Teale JM (2011) STAT6-/- mice exhibit decreased cells with alternatively activated macrophage phenotypes and enhanced disease severity in murine neurocysticercosis. J Neuroimmunol 232:26-34. CrossRef Medline

Mishra BB, Li Q, Steichen AL, Binstock BJ, Metzger DW, Teale JM, Sharma J (2013) Galectin-3 functions as an alarmin: pathogenic role for sepsis development in murine respiratory tularemia. PLoS One 8:e59616. CrossRef Medline

Mishra PK, Li Q, Munoz LE, Mares CA, Morris EG, Teale JM, Cardona AE (2016) Reduced leukocyte infiltration in absence of eosinophils correlates with decreased tissue damage and disease susceptibility in DeltadblGATA mice during murine neurocysticercosis. PLoS Negl Trop Dis 10:e0004787. CrossRef Medline

Mosser DM, Edwards JP (2008) Exploring the full spectrum of macrophage activation. Nat Rev Immunol 8:958-969. CrossRef Medline

Mukaro VR, Bylund J, Hodge G, Holmes M, Jersmann H, Reynolds PN, Hodge S (2013) Lectins offer new perspectives in the development of macrophage-targeted therapies for COPD/emphysema. PLoS One 8:e56147. CrossRef Medline

Murray PJ, Wynn TA (2011) Protective and pathogenic functions of macrophage subsets. Nat Rev Immunol 11:723-737. CrossRef Medline

Nakagawa Y, Chiba K (2015) Diversity and plasticity of microglial cells in psychiatric and neurological disorders. Pharmacol Ther 154:21-35. CrossRef Medline

Nash TE, Singh G, White AC, Rajshekhar V, Loeb JA, Proaño JV, Takayanagui OM, Gonzalez AE, Butman JA, DeGiorgio C, Del Brutto OH, DelgadoEscueta A, Evans CA, Gilman RH, Martinez SM, Medina MT, Pretell EJ, Teale J, Garcia HH (2006) Treatment of neurocysticercosis: current status and future research needs. Neurology 67:1120-1127. CrossRef Medline

Rabinovich GA, Baum LG, Tinari N, Paganelli R, Natoli C, Liu FT, Iacobelli S (2002) Galectins and their ligands: amplifiers, silencers or tuners of the inflammatory response? Trends Immunol 23:313-320. CrossRef Medline

Ransohoff RM, Kivisäkk P, Kidd G (2003) Three or more routes for leukocyte migration into the central nervous system. Nat Rev Immunol 3:569581. CrossRef Medline 
Rückerl D, Allen JE (2014) Macrophage proliferation, provenance, and plasticity in macroparasite infection. Immunol Rev 262:113-133. CrossRef Medline

Sano H, Hsu DK, Apgar JR, Yu L, Sharma BB, Kuwabara I, Izui S, Liu FT (2003) Critical role of galectin-3 in phagocytosis by macrophages. J Clin Invest 112:389-397. CrossRef Medline

Sato S, St-Pierre C, Bhaumik P, Nieminen J (2009) Galectins in innate immunity: dual functions of host soluble beta-galactoside-binding lectins as damage-associated molecular patterns (DAMPs) and as receptors for pathogen-associated molecular patterns (PAMPs). Immunol Rev 230: 172-187. CrossRef Medline

Shi C, Pamer EG (2011) Monocyte recruitment during infection and inflammation. Nat Rev Immunol 11:762-774. CrossRef Medline

Sperandio M, Gleissner CA, Ley K (2009) Glycosylation in immune cell trafficking. Immunol Rev 230:97-113. CrossRef Medline

Sun Y, Chauhan A, Sukumaran P, Sharma J, Singh BB, Mishra BB (2014) Inhibition of store-operated calcium entry in microglia by helminth factors: implications for immune suppression in neurocysticercosis. J Neuroinflammation 11:210. CrossRef Medline

Swamydas M, Luo Y, Dorf ME, Lionakis MS (2015) Isolation of mouse neutrophils. Curr Protoc Immunol 110:3.20.1-3.20.15. CrossRef Medline
Wang G, Zhang J, Hu X, Zhang L, Mao L, Jiang X, Liou AK, Leak RK, Gao Y, Chen J (2013) Microglia/macrophage polarization dynamics in white matter after traumatic brain injury. J Cereb Blood Flow Metab 33:18641874. CrossRef Medline

White AC Jr (1997) Neurocysticercosis: a major cause of neurological disease worldwide. Clin Infect Dis 24:101-113; quiz 114-115. Medline

White AC Jr (2000) Neurocysticercosis: updates on epidemiology, pathogenesis, diagnosis, and management. Annu Rev Med 51:187-206. CrossRef Medline

Wohlfert EA, Blader IJ, Wilson EH (2017) Brains and brawn: toxoplasma infections of the central nervous system and skeletal muscle. Trends Parasitol 33:519-531. CrossRef Medline

Wright RD, Souza PR, Flak MB, Thedchanamoorthy P, Norling LV, Cooper D (2017) Galectin-3-null mice display defective neutrophil clearance during acute inflammation. J Leukoc Biol 101:717-726. CrossRef Medline

Wynn TA, Vannella KM (2016) Macrophages in tissue repair, regeneration, and fibrosis. Immunity 44:450-462. CrossRef Medline

Yurdagul A Jr, Doran AC, Cai B, Fredman G, Tabas IA (2017) Mechanisms and consequences of defective efferocytosis in atherosclerosis. Front Cardiovasc Med 4:86. CrossRef Medline 